\title{
Finite element simulation of dispersion in the Bay of Santander
}

\author{
P. Tabuenca, J. Vila
}

\author{
J. Cardona
}

\&

A. Samartin

\begin{abstract}
Two mathematical models are used to simulate pollution in the Bay of Santander. The first is the hydrodynamic model that provides the velocity field and height of the water. The second gives the pollutant concentration field as a resultant. Both models are formulated in two-dimensional equations. Linear triangular finite elements are used in the Galerkin procedure for spatial discretization. A finite difference scheme is used for the time integration. At each time step the calculated results of the first model are input to the second model as field data. The efficiency and accuracy of the models are tested by their application to a simple illustrative example. Finally a case study in simulation of pollution evolution in the Bay of Santander is presented.
\end{abstract}

\section{INTRODUCTION}

The increase in urban and industrial occupation is the principal reason for the growth of pollution in rivers and near coastal zones.

There are several procedures for the study of water quality at a given instant and in a confined zone into which pollutant diffusors are poured. Physical models, ${ }^{1}$ statistical correlations, ${ }^{2}$ use of tracers ${ }^{3,4}$ and numerical methods, among others, are the procedures applied in practice.

The numerical methods are the most economical, and due to the increased computer availability they have been exclusively used during the last decades. The main techniques among numerical methods are finite differences and finite elements. Finite differences present some difficulties in modelling irregular boundaries, and earlier attempts, such as the one presented in Ref. 5, have been followed by recent applications. ${ }^{6}$ Finite element (FE) procedure usually demands large computational facilities due to the elevated number of nodes and elements necessary to model accurately a real situation with irregular geometry. This method is currently the most common numerical procedure for treating pollutant dispersion.

In general, two mathematical models to simulate pollution in estuaries and coastal zones are necessary: the hydrodynamic model and the dispersion model. The first provides the velocity field and height of the water. Those results are data for the second model, which provides the pollutant concentration field.

In this paper, FE techniques in the treatment of spatial discretization will be used and the finite differences in the time domain will be considered. In some cases the method of characteristics ${ }^{7}$ has been reported as being applied with success, but it presents in real cases some difficulties. The hydrodynamic model has been developed in several ways, and most of the trials considering the $3-\mathrm{D}^{8}$ situation have been tentative ones. The dispersion model typically introduces some assumptions regarding the type of pollutant, ${ }^{9}$ yellow pollutant or fine sand sediment. ${ }^{10}$ Here the pollutant has 




Fig. 1. Vertical cross-section of the water in the estuary.

been considered to be non-reactive with water and does not modify the bathymetry.

\section{THE HYDRODYNAMIC MODEL}

\subsection{Shallow water equations}

The continuity and momentum equations are the ones that govern the hydrodynamic behaviour of an estuary. Averaging the equations over the depth, discarding the terms due to friction and wind, and adapting for its treatment by means of the numerical model proposed in Ref. 11, we have the result

$$
\begin{aligned}
& \frac{\partial H}{\partial t}+\frac{\partial(H U)}{\partial x}+\frac{\partial(H V)}{\partial y}=0 \\
& \frac{\partial U}{\partial t}+U \frac{\partial U}{\partial x}+V \frac{\partial U}{\partial y}-f V+g \frac{\partial \zeta}{\partial x}=0 \\
& \frac{\partial V}{\partial t}+U \frac{\partial V}{\partial x}+V \frac{\partial V}{\partial y}+f U+g \frac{\partial \zeta}{\partial y}=0
\end{aligned}
$$

where $H$ is the height of the water surface with respect to the bottom of the estuary, $\zeta$ is the elevation of the surface of the water over the mean surface level, $U$ and $V$ are the cartesian components of the velocity averaged over $H, g$ is the acceleration due to gravity, and $f$ is the Coriolis parameter (Fig. 1).

To resolve this set of equations, it is necessary to prescribe the boundary conditions:

(i) For open boundary:

$$
\zeta=\bar{\zeta}
$$

(ii) For fixed boundary the normal velocity component:

$$
v_{\mathrm{n}}=0
$$

Also the following initial conditions at all points of the domain are specified:

$$
\zeta(0)=\bar{\zeta}_{0} ; \quad U(0)=\bar{U}_{0} ; \quad V(0)=\bar{V}_{0}
$$

\subsection{Finite element model}

To obtain an approximate solution of the initial boundary value problem, a weak formulation based on the Galerkin method is used. According to the technique of the finite elements, the unknown $\zeta, U, V$ are expanded by means of the expressions:

$$
\begin{gathered}
\zeta \approx \sum_{j=1}^{M} \zeta_{j}(t) \Phi_{j}(x, y) \\
U \approx \sum_{j=1}^{M} U_{j}(t) \Phi_{j}(x, y) \\
V \approx \sum_{j=1}^{M} V_{j}(t) \Phi_{j}(x, y)
\end{gathered}
$$

The remaining parameters are approximated using the same interpolation functions. Thus, the basis functions $\Phi_{j}(x, y)$ are given in each element by:

$$
\Phi_{j}=\frac{1}{2 \Delta^{e}}\left(a_{j}+b_{j} x+c_{j} y\right)
$$

where $\Delta^{\mathrm{e}}$ is the area of the element ' $e$ ' (Fig. 2)

$$
\Delta^{\mathrm{e}}=\frac{b_{2} c_{3}-b_{3} c_{2}}{2}
$$

and the coefficients are

$$
\begin{aligned}
a_{i} & =x_{j} y_{k}-x_{k} y_{j} \\
b_{i} & =y_{j}-y_{k} \\
c_{i} & =x_{k}-x_{j}
\end{aligned}
$$

Substituting eqne (7)-(9) in (1), (2) and (3), we can obtain the element equations for each triangle $\Delta^{\mathrm{e}}$ :

$$
\begin{aligned}
& \sum_{i} M_{i j}^{\mathrm{e}} \dot{\zeta}_{i}-\sum_{i, k} X_{i k j}^{\mathrm{e}} U_{i} H_{k}-\sum_{i, k} Y_{i k j}^{\mathrm{e}} V_{i} H_{k} \\
& =-\sum_{i} R_{i j}^{\mathrm{e}} H_{i} \\
& \sum_{i} M_{i j}^{\mathrm{e}} \dot{U}_{i}+\sum_{i, k} X_{j i k}^{\mathrm{e}} U_{i} U_{k}+\sum_{i, k} Y_{j i k}^{\mathrm{e}} V_{i} U_{k} \\
& -\sum_{i, k} N_{j i k}^{\mathrm{e}} f_{i} V_{k}+g \sum_{i} P_{j i} \zeta_{i}=0
\end{aligned}
$$

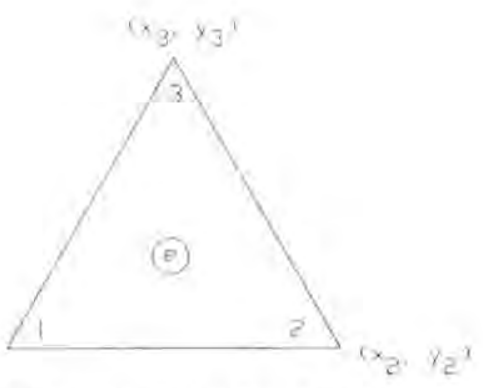

Fig. 2. Linear triangular element. 


$$
\begin{gathered}
\sum_{i} M_{i j}^{\mathrm{e}} \dot{V}_{i}+\sum_{i, k} X_{j i k}^{\mathrm{e}} U_{i} V_{k}+\sum_{i, k} Y_{j i k}^{\mathrm{e}} V_{i} V_{k} \\
+\sum_{i, k} N_{j i k}^{\mathrm{e}} f_{i} U_{k}+g \sum_{i} Q_{j i} \zeta_{i}=0
\end{gathered}
$$

Matrices are given by

$$
\begin{aligned}
M_{j i}^{\mathrm{e}} & =\int_{\mathrm{e}} \phi_{j} \phi_{i} \mathrm{~d} \Omega=\frac{\Delta^{\mathrm{e}}}{12}\left(1+\delta_{j i}\right) \\
X_{j i k}^{\mathrm{e}} & =\int_{\mathrm{e}} \phi_{j} \phi_{i} \frac{\partial \phi_{k}}{\partial x} \mathrm{~d} \Omega=\frac{b_{k}}{24}\left(1+\delta_{j i}\right) \\
Y_{j i k}^{\mathrm{e}} & =\int_{\mathrm{e}} \phi_{j} \phi_{i} \frac{\partial \phi_{k}}{\partial y} \mathrm{~d} \Omega=\frac{c_{k}}{24}\left(1+\delta_{j i}\right) \\
N_{j i k}^{\mathrm{e}} & =\int_{\mathrm{e}} \phi_{j} \phi_{i} \phi_{k} \mathrm{~d} \Omega \\
P_{j i}^{\mathrm{e}} & =\int_{\mathrm{e}} \phi_{j} \frac{\partial \phi_{i}}{\partial x} \mathrm{~d} \Omega=\frac{b_{i}}{6} \\
Q_{j i}^{\mathrm{e}} & =\int_{\mathrm{e}} \phi_{j} \frac{\partial \phi_{i}}{\partial y} \mathrm{~d} \Omega=\frac{c_{i}}{6} \\
R_{j i}^{\mathrm{e}} & =\int_{\Gamma_{V}^{\mathrm{e}}} \phi_{j} \phi_{i} V_{n} \mathrm{~d} \Gamma=\frac{\Gamma_{V}^{\mathrm{e}}}{6}\left(1+\delta_{j i}\right) V_{n}
\end{aligned}
$$

\begin{tabular}{|c|c|c|c|c|c|c|c|c|c|}
\hline & & $=1$ & & & $=$ & & & $=3$ & \\
\hline & & $j$ & & & $j$ & & & $j$ & \\
\hline & 6 & 2 & 2 & 2 & 2 & 1 & 2 & 1 & $\overline{2}$ \\
\hline$i$ & 2 & 2 & 1 & 2 & 6 & 2 & 1 & 2 & 2 \\
\hline & 2 & 1 & 2 & 1 & 2 & 2 & 2 & 2 & 6 \\
\hline
\end{tabular}

\section{Matrix $N_{i j k}$ is shown in Table 1.}

Once the element equations are assembled and the boundary conditions are introduced, the nonlinear

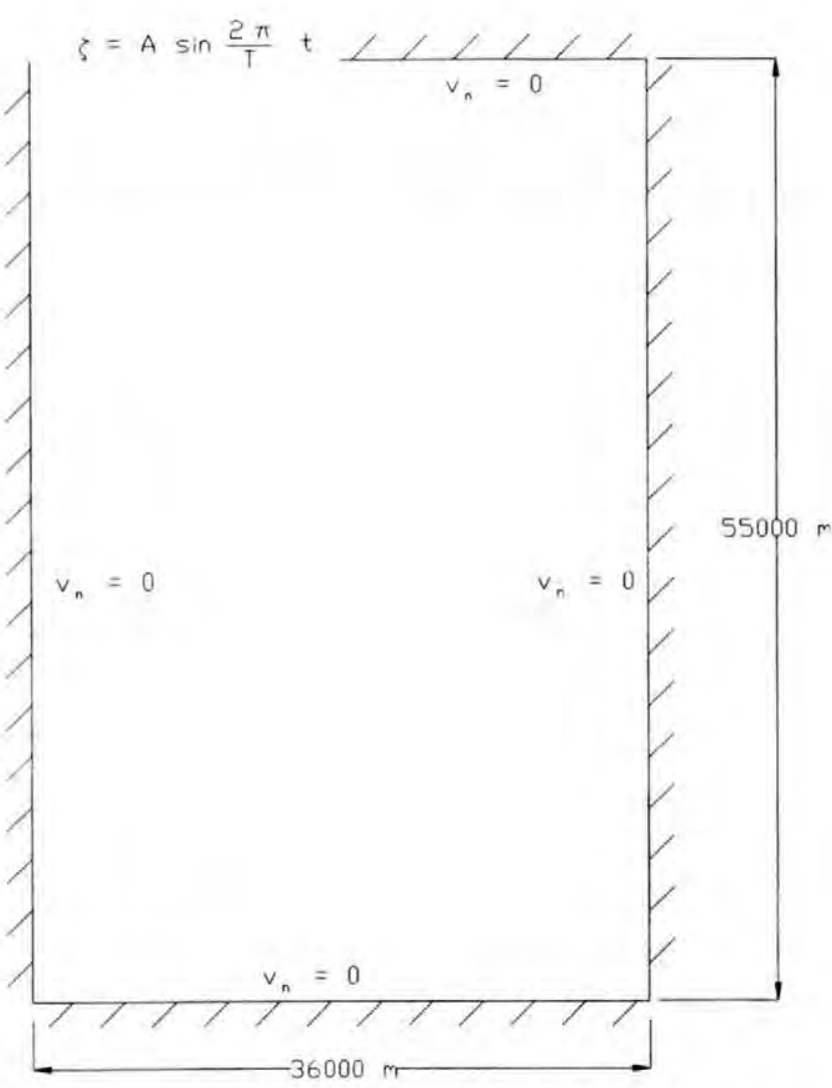

Fig. 3. Rectangular bay.
Table 1. Matrix $N_{i j k}^{\mathrm{e}}$. Each entry is multiplied by $\Delta^{\mathrm{e}} / 60$

simultaneous equations system is derived:

$$
\begin{aligned}
& {[M]\{\dot{\zeta}\}-[A(U, V)]\{H\}=-[R]\{H\}} \\
& {[M]\{\dot{U}\}+[B(U, V)]\{U\}-[N]\{V\}+g[P]\{\zeta\}=0} \\
& {[M]\{\dot{V}\}+[B(U, V)]\{V\}+[N]\{U\}+g[Q]\{\zeta\}=0}
\end{aligned}
$$

\subsection{Time integration}

For the time integration, a finite difference scheme has

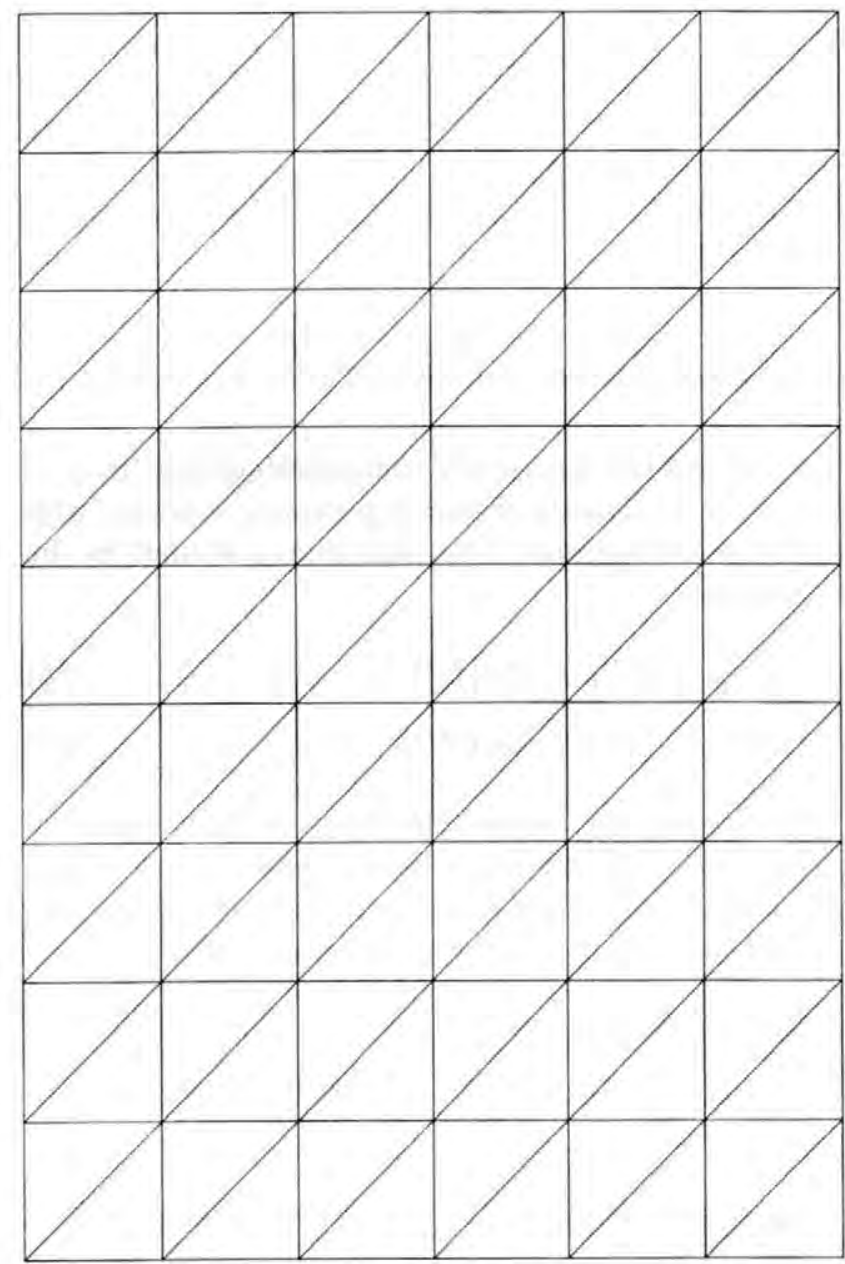

Fig. 4. Rectangular bay, FE mesh. 


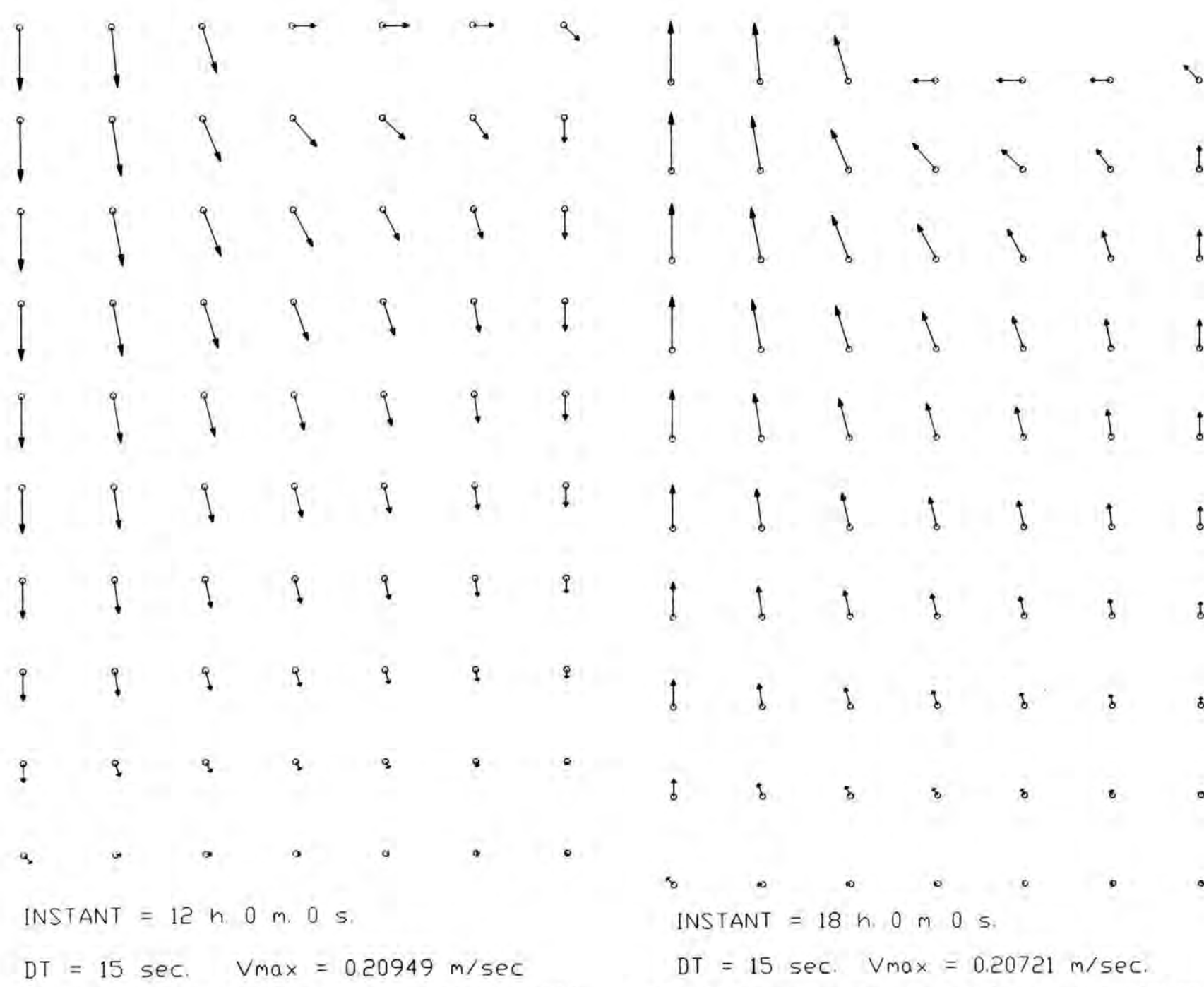

Fig. 5. Rectangular bay, velocity field at $t=12 \mathrm{~h}$ (flood tide).

been applied to increase the computational efficiency of the model. It consists of two-step explicit schemes, with second-order precision. This algorithm is defined by the expressions:

$$
\begin{aligned}
& \left\{U^{n+\frac{1}{2}}\right\}=\left\{U^{n}\right\}+\frac{1}{2} \Delta t\left\{\dot{U}^{n}\right\} \\
& \left\{U^{n+1}\right\}=\left\{U^{n}\right\}+\Delta t\left\{\dot{U}^{n+\frac{1}{2}}\right\}
\end{aligned}
$$

Multiplying the matrix $[M]$ from the left, replacing $[M]$ on the left-hand side with its lumped mass matrix $[\bar{M}]$ and on the right-hand side with the selectively lumped mass matrix $[\tilde{M}]$, we have the results: ${ }^{12}$

$$
\begin{aligned}
& {[\bar{M}]\left\{U^{n+\frac{1}{2}}\right\}=[\tilde{M}]\left\{U^{n}\right\}} \\
& \quad=\frac{1}{2} \Delta t\left(\left[B\left(U^{n}, V^{n}\right)\right]\left\{U^{n}\right\}-[N]\left\{V^{n}\right\}+g[P]\left\{\zeta^{n}\right\}\right) \\
& {[\bar{M}]\left\{U^{n+1}\right\}=[\tilde{M}]\left\{U^{n}\right\}-\Delta t\left(\left[B\left(U^{n+\frac{1}{2}}, V^{n+\frac{1}{2}}\right)\right]\left\{U^{n+\frac{1}{2}}\right\}\right.} \\
& \left.\quad-[N]\left\{V^{n+\frac{1}{2}}\right\}+g[P]\left\{\zeta^{n+\frac{1}{2}}\right\}\right)
\end{aligned}
$$

Fig. 6. Rectangular bay, velocity field at $t=18 \mathrm{~h}$ (ebb tide).

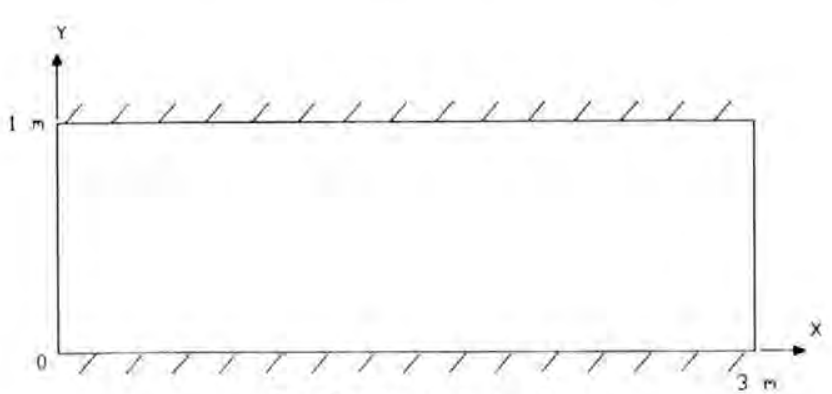

Fig. 7. Open channel.

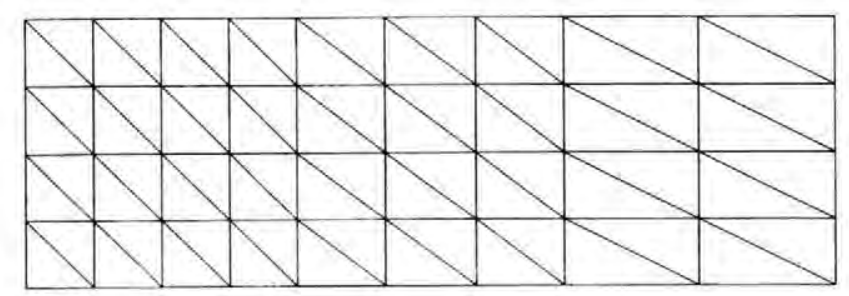

Fig. 8. Open channel, FE mesh. 
In a similar way, we have:

$$
\begin{aligned}
& {[\bar{M}]\left\{V^{n+\frac{1}{2}}\right\}=[\tilde{M}]\left\{V^{n}\right\}-\frac{1}{2} \Delta t\left(\left[B\left(U^{n}, V^{n}\right)\right]\left\{V^{n}\right\}\right.} \\
& \left.\quad+[N]\left\{U^{n}\right\}+g[Q]\left\{\zeta^{n}\right\}\right) \\
& {[\bar{M}]\left\{V^{n+1}\right\}=[\tilde{M}]\left\{V^{n}\right\}-\Delta t\left(\left[B\left(U^{n+\frac{1}{2}}, V^{n+\frac{1}{2}}\right)\right]\left\{V^{n+\frac{1}{2}}\right\}\right.} \\
& \left.\quad+[N]\left\{U^{n+\frac{1}{2}}\right\}+g[Q]\left\{\zeta^{n+\frac{1}{2}}\right\}\right)
\end{aligned}
$$

and

$$
\begin{aligned}
& {[\bar{M}]\left\{\zeta^{n+\frac{1}{2}}\right\}=[\tilde{M}]\left\{\zeta^{n}\right\}} \\
& \quad+\frac{1}{2} \Delta t\left(\left[A\left(U^{n}, V^{n}\right)\right]\left\{H^{n}\right\}-[R]\left\{H^{n}\right\}\right) \\
& {[\bar{M}]\left\{\zeta^{n+1}\right\}=[\tilde{M}]\left\{\zeta^{n}\right\}} \\
& \quad+\Delta t\left(\left[A\left(U^{n+\frac{1}{2}}, V^{n+\frac{1}{2}}\right)\right]\left\{H^{n+\frac{1}{2}}\right\}-[R]\left\{H^{n+\frac{1}{2}}\right\}\right)
\end{aligned}
$$

From eqns (27)-(32), values of the unknowns $U^{n+1}$, $V^{n+1}$ and $\zeta^{n+1}$ can be obtained as functions of their values at the previous time step, i.e. $U^{n}, V^{n}$ and $\zeta^{n}$. Using this step-by-step procedure and considering the initial conditions (6), the unknown values at each time can be found.

\section{THE DISPERSION MODEL}

\subsection{Dispersion equation}

The distributed contaminant process satisfies the mass transfer equation, which includes transportation, diffusion and reaction sub-processes. Averaging the equation over the depth ${ }^{13}$ and using the continuity equation (1), we can obtain:

$$
\begin{aligned}
& \frac{\partial(H \Theta)}{\partial t}+\frac{\partial(H U \Theta)}{\partial x}+\frac{\partial(H V \Theta)}{\partial y}-\frac{\partial}{\partial x}\left(H D_{x} \frac{\partial \Theta}{\partial x}\right) \\
& -\frac{\partial}{\partial y}\left(H D_{y} \frac{\partial \Theta}{\partial y}\right)-H F+\alpha \Theta H-H \sum_{j} Q_{j} \delta_{j}=0
\end{aligned}
$$

where $\Theta$ is the concentration averaged in depth, $D_{x}$ and $D_{y}$ are the dispersion coefficients, $F$ is the rate of distributed source or mass production per unit mass and per unit time, $\alpha$ is the constant of generation or decay, and $Q_{j} \delta_{j}$ is the term in which the drains or prompt mass sources are included. ${ }^{14}$

Three types of boundary condition can be considered:

(i) $\Theta=\bar{\Theta}$ at points along the coast with imposed concentration

(ii) $q=\bar{q}_{n}$ at points of the border portion $\Gamma_{q}$ where the flow is specified

(iii) $q=\gamma\left(\Theta-\Theta_{\mathrm{e}}\right)$ at points of the coast with nonreflexive or absorbent border

where $\gamma$ is the transmissivity coefficient of the boundary ${ }^{12}$ and $\Theta_{e}$ is some reference concentration. In this case this term is negligible and it will not be considered.



Fig. 9. Concentration curves, $\Delta t=0 \cdot 1 \mathrm{~s}$.

Finally, the initial conditions for all domain points are:

$$
\Theta_{t=0}=\bar{\Theta}_{0}
$$

Application of the Galerkin method and the Green theorem give the weak formulation

$$
\begin{gathered}
\int_{\Omega} \frac{\partial \Theta}{\partial t} \Phi_{i} \mathrm{~d} \Omega+\int_{\Omega}\left(U \frac{\partial \Theta}{\partial x}+V \frac{\partial \Theta}{\partial y}\right) \Phi_{i} \mathrm{~d} \Omega \\
-\int_{\Omega}\left[H D_{x} \frac{\partial \Theta}{\partial x} \frac{\partial \frac{\Phi_{i}}{\partial}}{\partial x}+H D_{y} \frac{\partial \Theta}{\partial y} \frac{\partial \frac{\Phi_{i}}{H}}{\partial y}\right] \mathrm{d} \Omega \\
-\int_{\Omega} F \Phi_{i} \mathrm{~d} \Omega-\int_{\Omega} \alpha \Theta \Phi_{i} \mathrm{~d} \Omega-\int_{\Gamma_{q}} \Phi_{i} \bar{q}_{n} \mathrm{~d} \Gamma \\
-\int_{\Omega}\left(\sum_{k} Q_{k} \delta_{k}\right) \Phi_{i} \mathrm{~d} \Omega=0
\end{gathered}
$$

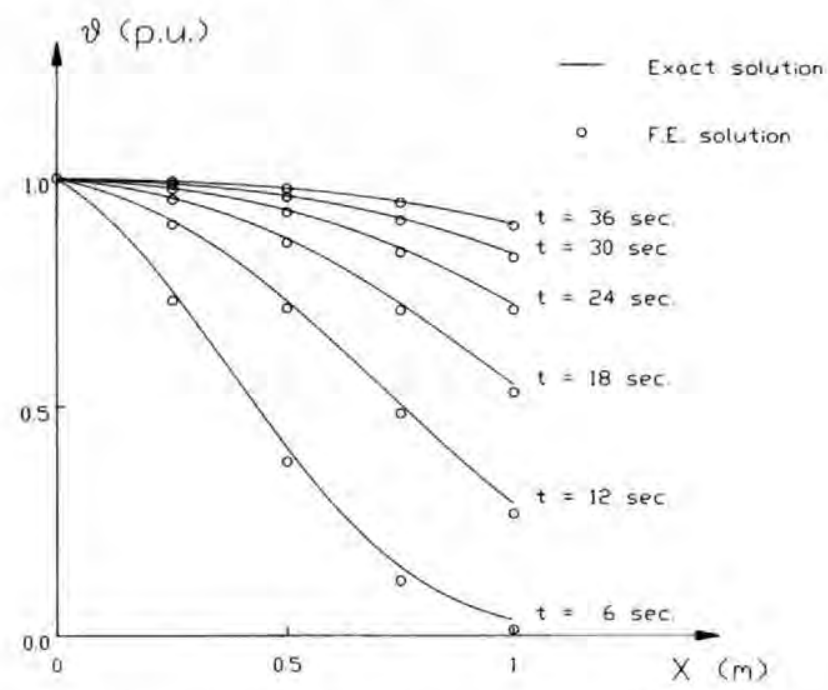

Fig. 10. Concentration curves, $\Delta t=1 \mathrm{~s}$. 


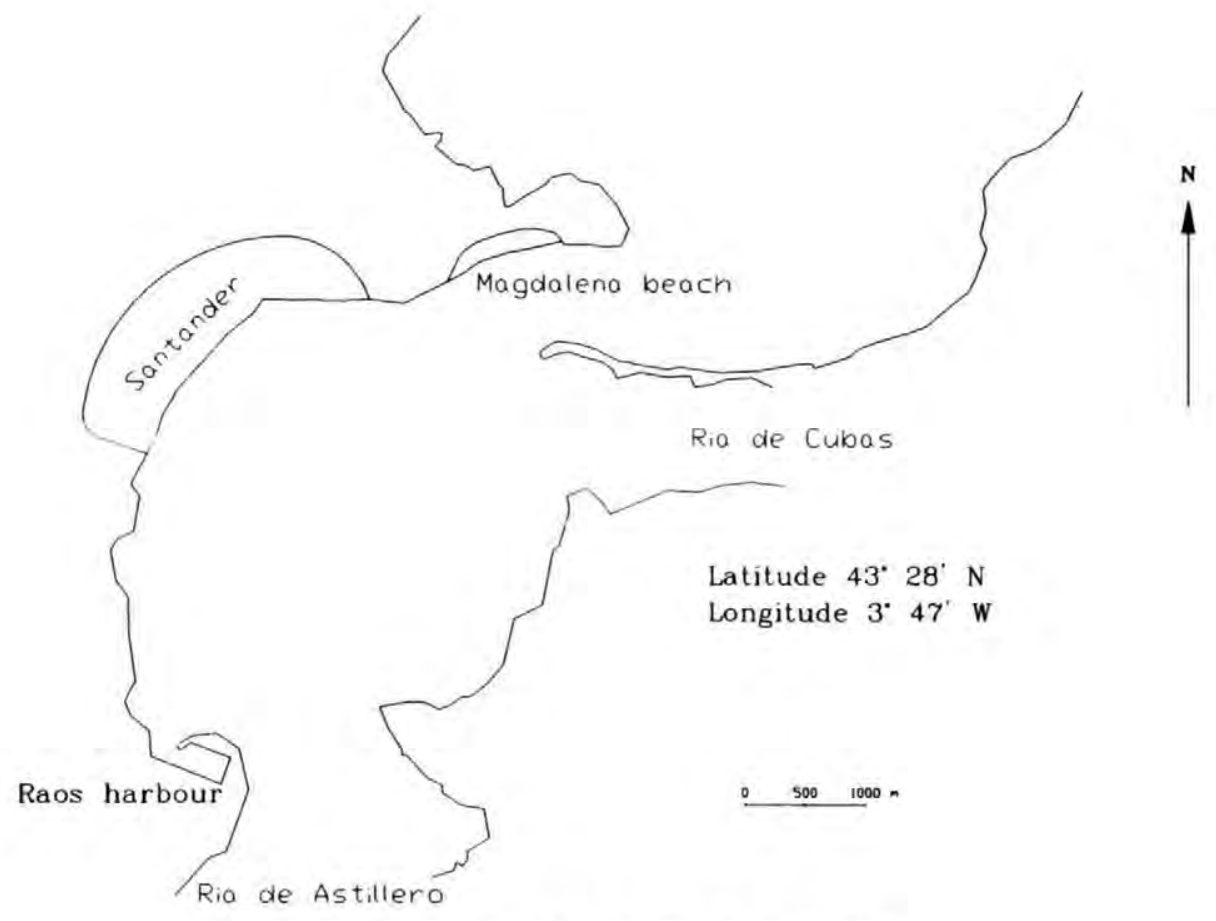

Fig. 11. Geometry of the Bay of Santander.

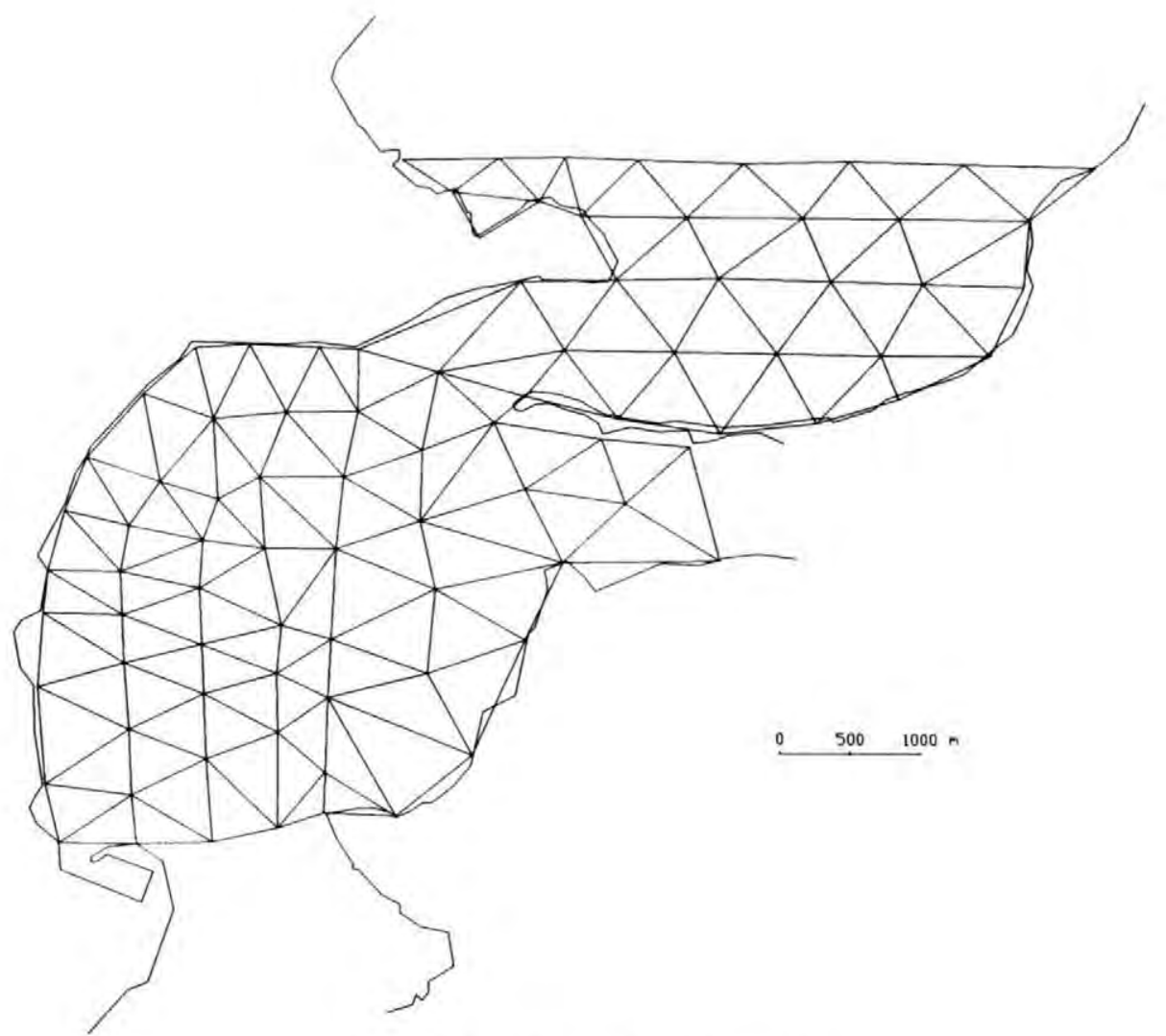

Fig. 12. Bay of Santander, FE mesh. 


\subsection{Finite element model}

The approximate form of the solution is

$$
\Theta=\sum_{j=1}^{N} \Theta_{j} \Phi_{j}
$$

where the global basis functions are the ones previously defined.

The remaining parameters are interpolated using the same shape functions as the previous model, and with triangular linear elements, eqn (35) is expressed in compact form:

$$
(M)\left\{\frac{\mathrm{d} \Theta}{\mathrm{d} t}\right\}=\left\{E_{\Theta}\right\}
$$

\subsection{Time integration}

For time integration, the equation is solved by finite differences. This leads to the following matrix equation

$$
[M]\{\Theta\}_{t+\Delta t}=[M]\{\Theta\}_{1}+\frac{1}{2} \Delta t\left\{E_{\Theta}\right\}_{t+\Delta t}+\frac{1}{2} \Delta t\left\{E_{\Theta}\right\}_{l}
$$

This nonlinear equation is solved iteratively, using the known values of $\{\Theta\}_{l}$ as well as evaluation of $\{\Theta\}_{1+\Delta l}$. Once the boundary conditions are inserted, an updated $\{\Theta\}_{t+\Delta t}$ is calculated. This vector is resolved iteratively, until a specified level of tolerance is reached. ${ }^{15}$ With the computed vector $\{\Theta\}_{1+\Delta t}$, the solution for the current instant $t+\Delta t$ is found from the expression (36), which expresses the concentration interpolated at every point of the estuary.

\section{NUMERICAL EXPERIMENTATION}

\subsection{Hydrodynamics of a rectangular bay}

In order to validate the hydrodynamic model, the

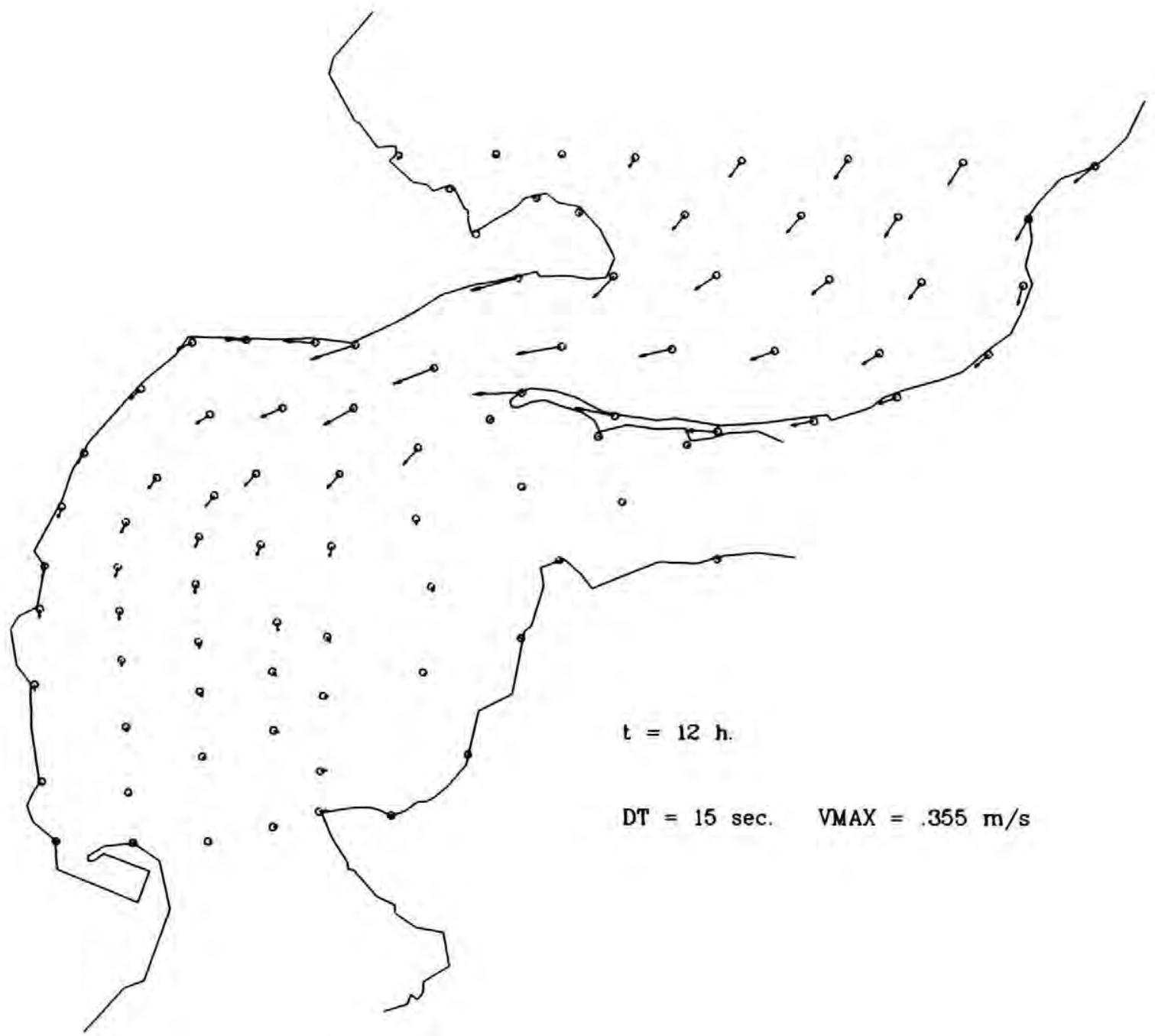

Fig. 13. Velocity field (flood tide). 
following simple example of a bay circulation will be analysed. The rectangular bay, with dimensions $36000 \times$ $55000 \mathrm{~m}$, is represented in Fig. 3. The depth is $36 \mathrm{~m}$ and the entrance of the bay, placed to the west of its northern border, has a length of $18000 \mathrm{~m}$. The bay is discretized into 108 elements with a total of 70 nodes, as shown in Fig. 4. The tide amplitude has the value $A=2 \mathrm{~m}$, with $T=12 \mathrm{~h}$ being its period. Time integration has been made taking an interval $\Delta t=15 \mathrm{~s}$. At the initial time, unknowns were assumed to be zero, verifying a cold starter.

The velocity field is represented in Figs 5 and 6 at instants $t=12$ and $18 \mathrm{~h}$ after the initial instant, which correspond to the moments at which the tide is ascending and the level of the water is null, high tide, descending tide and null level of the water and low tide, respectively. All these results are in good agreement with those shown in Ref. 11 using another numerical model.

\subsection{Propagation of a conservative substance through an open channel}

The concentration evolution of a conservative substance along an open channel with no sources is studied. The channel is represented in Fig. 7. The concentration of a conservative substance for $x=0$ is supposed to be known and it is imposed to the value $\theta=1$, while for $x(x<0 \leq 3) \mathrm{m}$ the initial concentration is null. The velocity of the fluid is uniform in the whole domain. The domain is discretized by a mesh having 50 nodes and 72 elements, shown in Fig. 8. For a better representation of the concentration variations, the mesh has to be discretized more finely at the extreme at which the concentration gradient is greater. Program data are given in Table 2.

The exact solution for this case ${ }^{16}$ is that given by the equation

$$
\theta(x, t)=\frac{1}{2} \text { fcer }\left[\frac{x-U t}{2\left(D_{x} t\right)^{1 / 2}}\right]+\frac{1}{2} \mathrm{e}^{U x / D_{x}} \text { fcer }\left[\frac{x+U t}{2\left(D_{x} t\right)^{1 / 2}}\right]
$$

The transient solution for times $t=6,12,18,24,30$ and $36 \mathrm{~s}$ is studied. The size of the interval $\Delta t$ has been

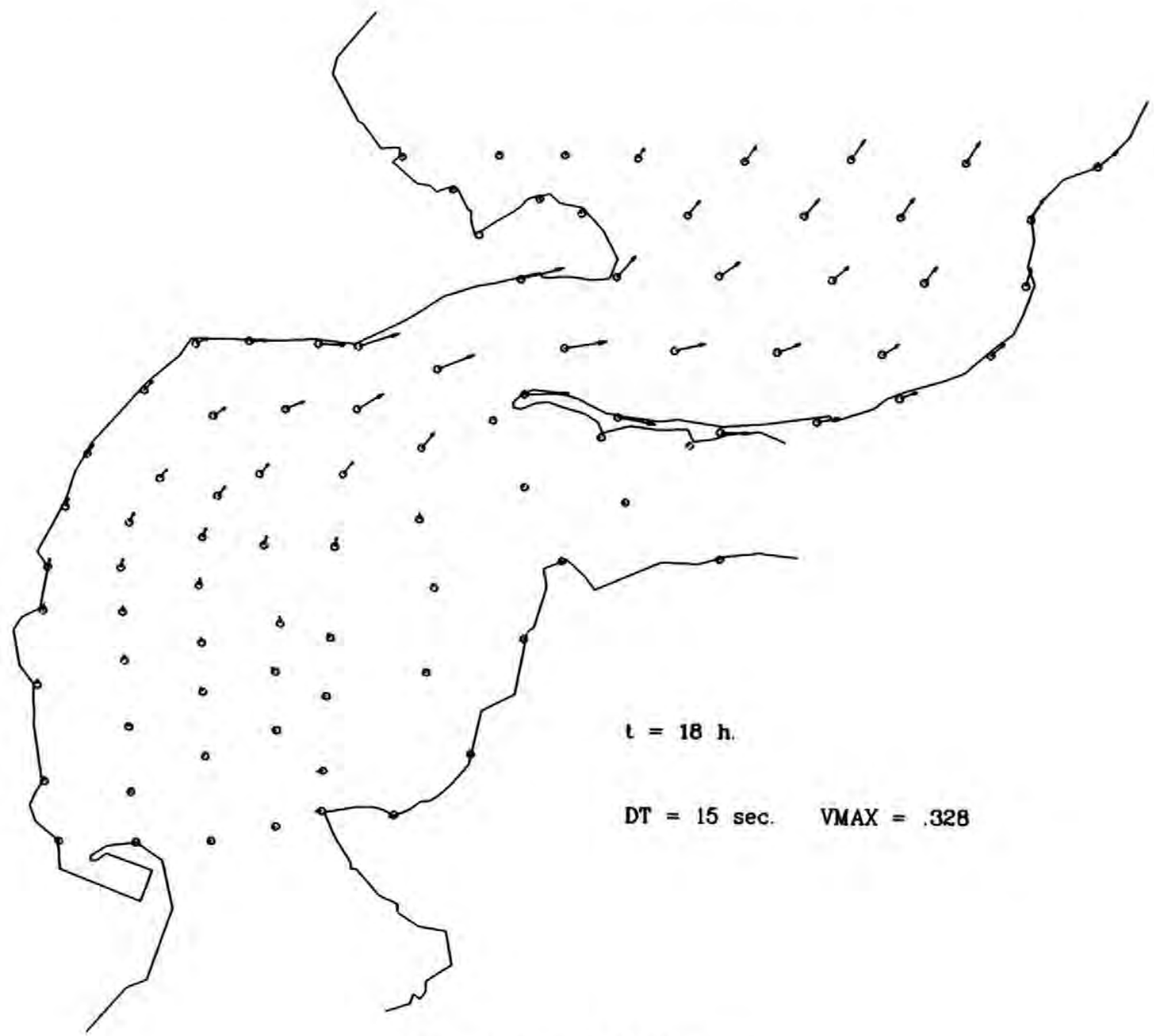

Fig. 14. Velocity field (ebb tide). 
Table 2. Open channel data

\begin{tabular}{lcccccc}
\hline $\begin{array}{l}\text { Velocity } \\
(\mathrm{m} / \mathrm{s})\end{array}$ & $\begin{array}{l}\text { Dispersion } \\
\text { coefficient } \\
\left(\mathrm{m}^{2} / \mathrm{s}\right)\end{array}$ & $\begin{array}{c}\text { Depth } \\
(\mathrm{m})\end{array}$ & $\begin{array}{c}\text { Concentration } \\
\rho_{1} / \rho\end{array}$ \\
\hline$U$ & $V$ & $D_{x}$ & $D_{y}$ & $h$ & $\theta(x=0)$ & $\theta_{0}(0<x \leq 3 \mathrm{~m})$ \\
\hline 0.05 & 0.00 & 0.01 & 0.00 & 1.00 & 1.00 & 0.00 \\
\hline
\end{tabular}

selected by using the following empirical expressions: ${ }^{17}$

$$
\begin{aligned}
& \Delta t \leq K_{1} \frac{\Delta x}{v} \\
& \Delta t \leq K_{2} \frac{\Delta x^{2}}{2 D}
\end{aligned}
$$

where $K_{1}$ and $K_{2}$ are numbers to be specified later, $\Delta x$ is the shorter length of an element's side, $v$ is the velocity of the fluid and $D$ is the dispersion coefficient.

Figures 9 and 10 represent the transient solution obtained with the model using the time intervals
$\Delta t=0.1 \mathrm{~s}$ and $1.0 \mathrm{~s}$. These results are compared in the figures with the exact one given by eqn (39). It is interesting to point out that for $\Delta t=1.5 \mathrm{~s}$, the numerical model becomes unstable. That means the coefficients $K_{1}$ and $K_{2}$ of formula (40) can be estimated as 0.2 and 0.3 , respectively, for maximum $\Delta t=1.0 \mathrm{~s}$.

\section{APPLICATION TO THE BAY OF SANTANDER}

\subsection{Hydrodynamies of the Bay}

The geometry of the Bay of Santander is shown in Fig. 11. The domain of the Bay is discretized into 130 elements and 89 nodes, as Fig. 12 shows. The boundary conditions imposed on the hydrodynamic model are:

(i) level of the northern border of oceanic nodes: $\zeta=2 \cdot 0 \sin 2 \pi / 44640 t$

(ii) southern border nodes: $v=0$

(iii) land borders: $v_{n}=0$

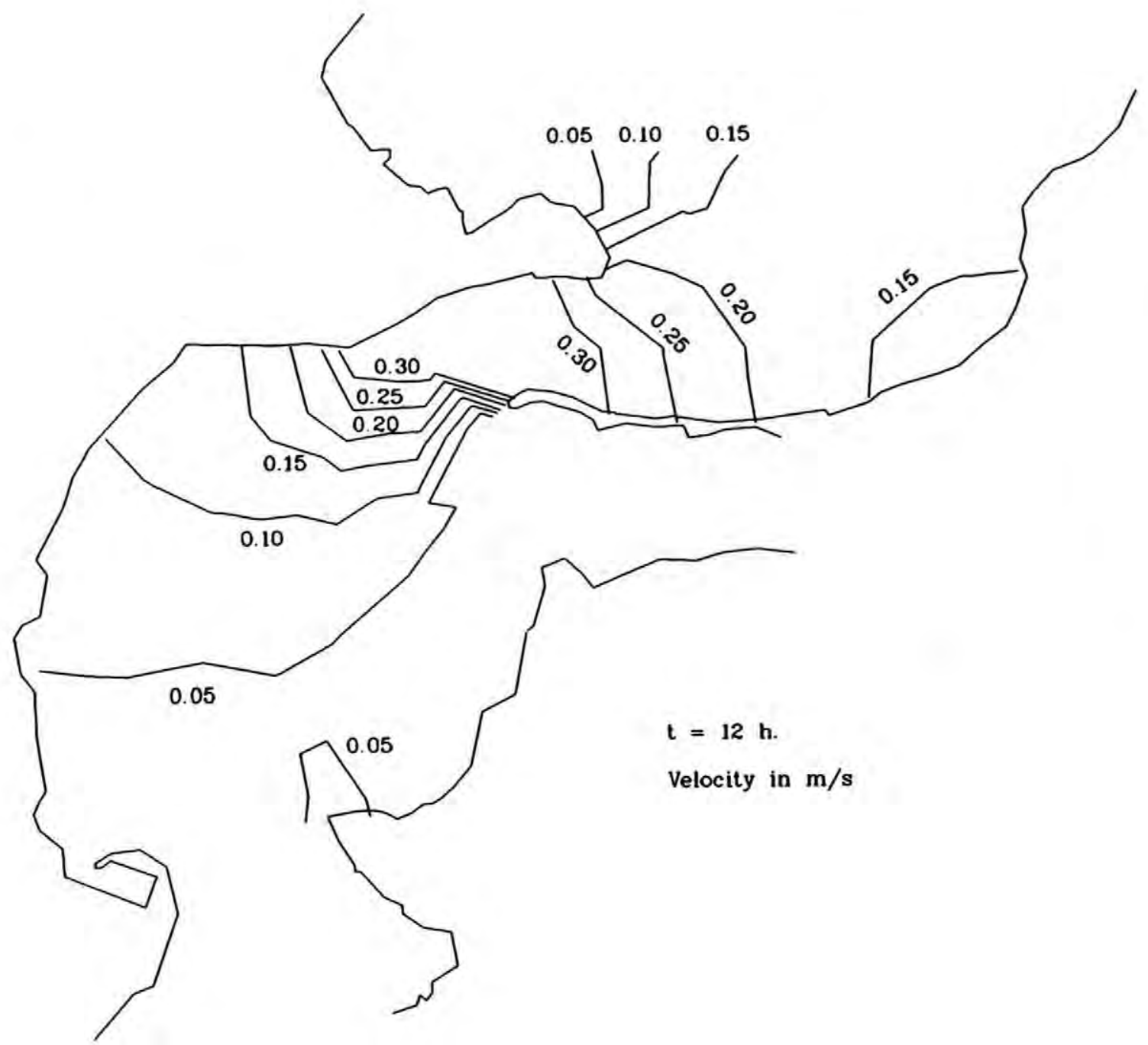

Fig. 15. Velocity isolines (flood tide). 
The initial conditions correspond to the cold starter, i.e. the sea elevation and the velocities are assumed to be zero at initial time.

A hydrodynamic study of the Bay has been carried out and some results are represented in the following figures. In Figs 13 and 14 the speed of the water is given in all the nodes for the flood and ebb tides. The maximum value obtained for the speed is $35.5 \mathrm{~cm} / \mathrm{s}$. In Figs 15 and 16 the constant speed isolines are plotted in the same instants. It can be observed that the greater variations of the speed correspond to the abrupt border zone, where the speed gradient is maximum.

\subsection{Conservative substance}

Contamination due to conservative substances is studied. The effect of the entry, via the estuary of Astillero, of a conservative substance with concentration unity has been modelled during two tidal cycles. Then the following conditions were imposed. Unity concentration at corresponding nodes along the border of the estuary of
Astillero and zero concentration at nodes of the oceanic border where it is supposed that the water coming from the open sea is free of contamination. For data that define the properties of the medium, the values $D_{x}=D_{y}=10^{3} \mathrm{~m}^{2} / \mathrm{s}$ have been used. The interval has the value $\Delta t=15 \mathrm{~s}$. The computed results are shown in Figs 17-20 where isolines of constant concentration are represented in the instants corresponding to flood tide, high tide, ebb tide and low tide, respectively. The results show a cyclical variation of the concentration with, approximately, the same period of the tide, as illustrated in Fig. 21 where the evolution of the concentration as a function of time on the shore next to the city of Santander is presented.

\subsection{Evolution of a bacterium population}

The evolution of a bacterium population in the Bay, with known concentration at the border of the Astillero estuary, is studied. In order to include the death of some bacteria, a decay coefficient $\alpha$ is used. On the oceanic

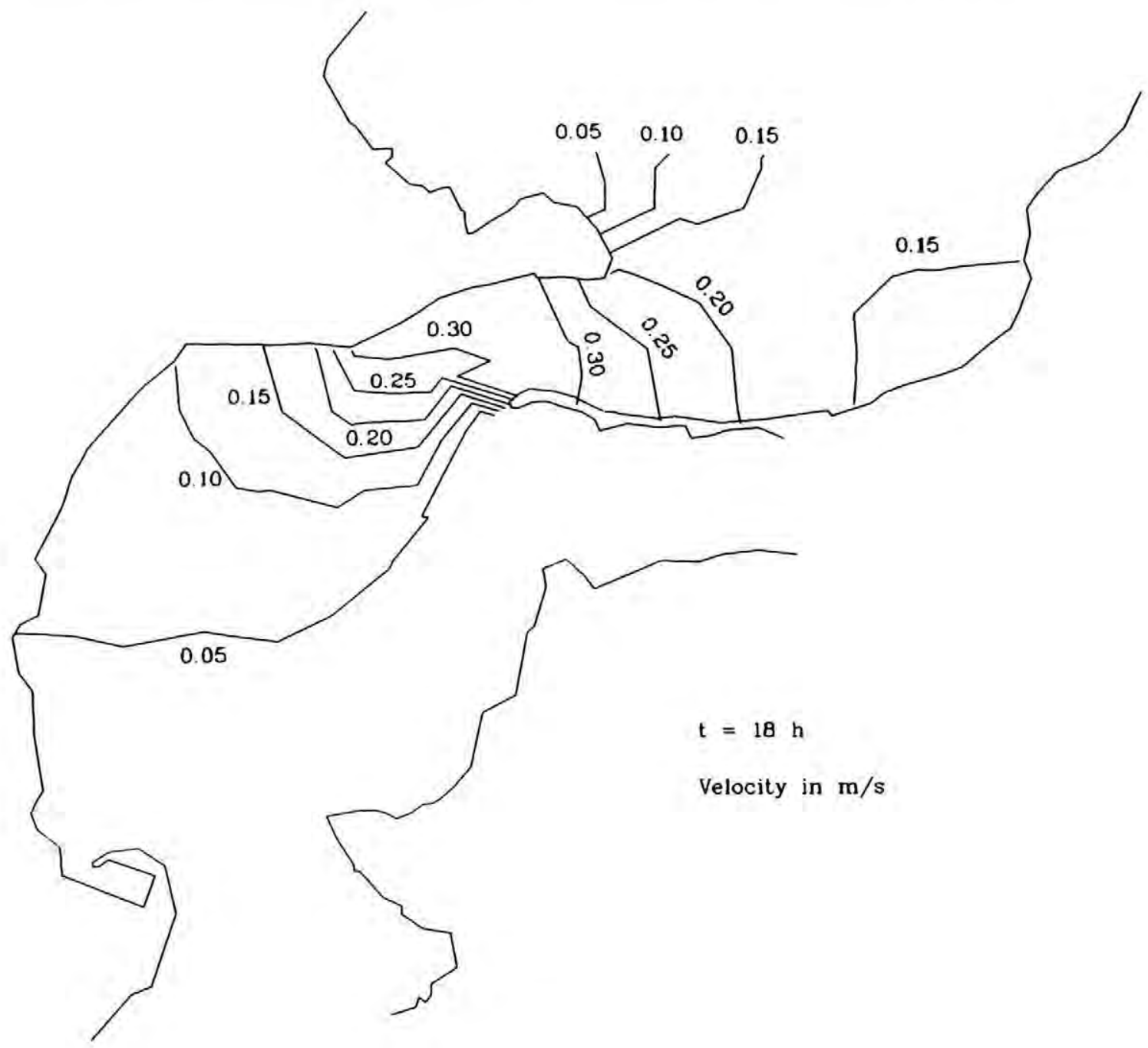

Fig. 16. Velocity isolines (ebb tide). 


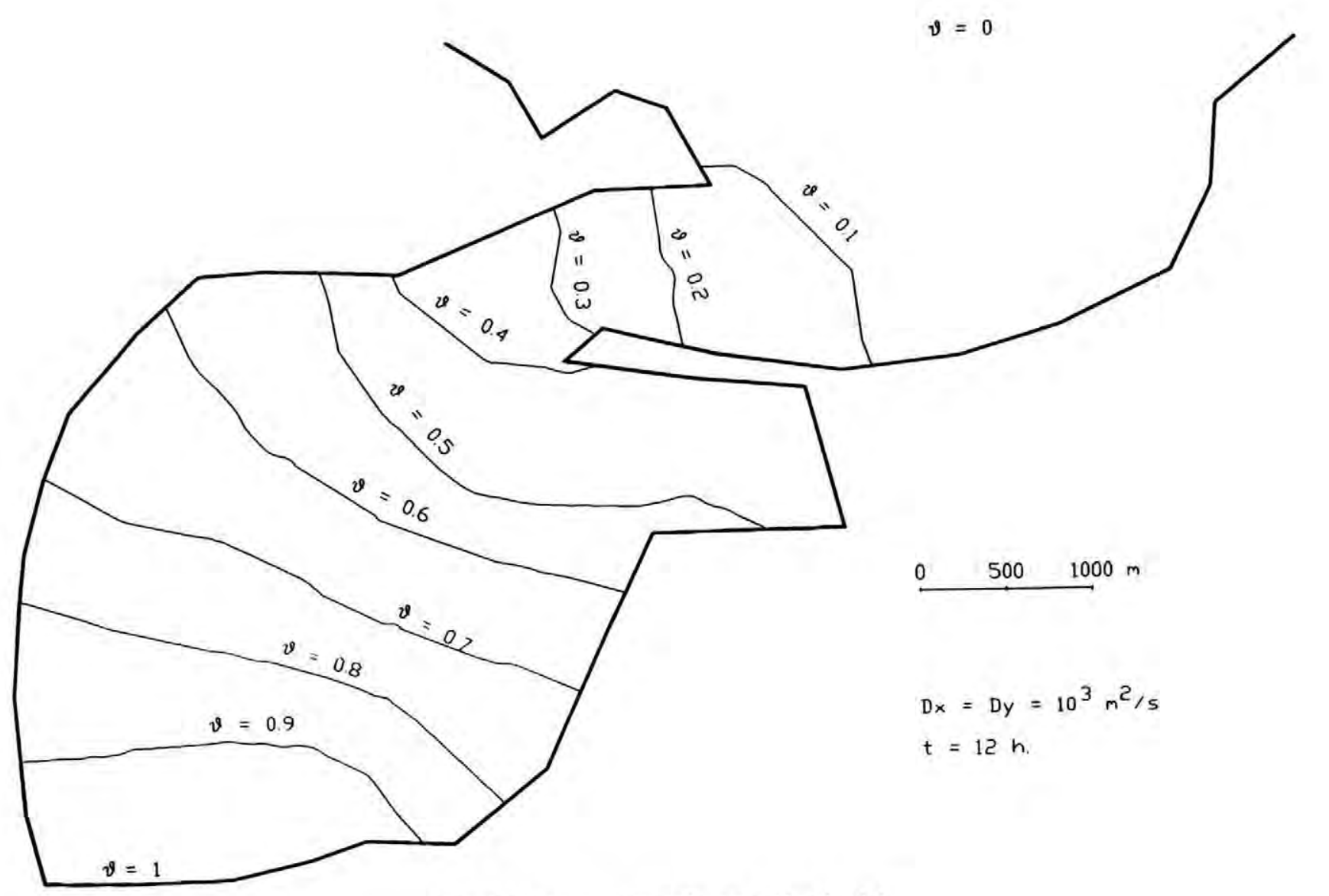

Fig. 17. Conservative substance (flood tide).

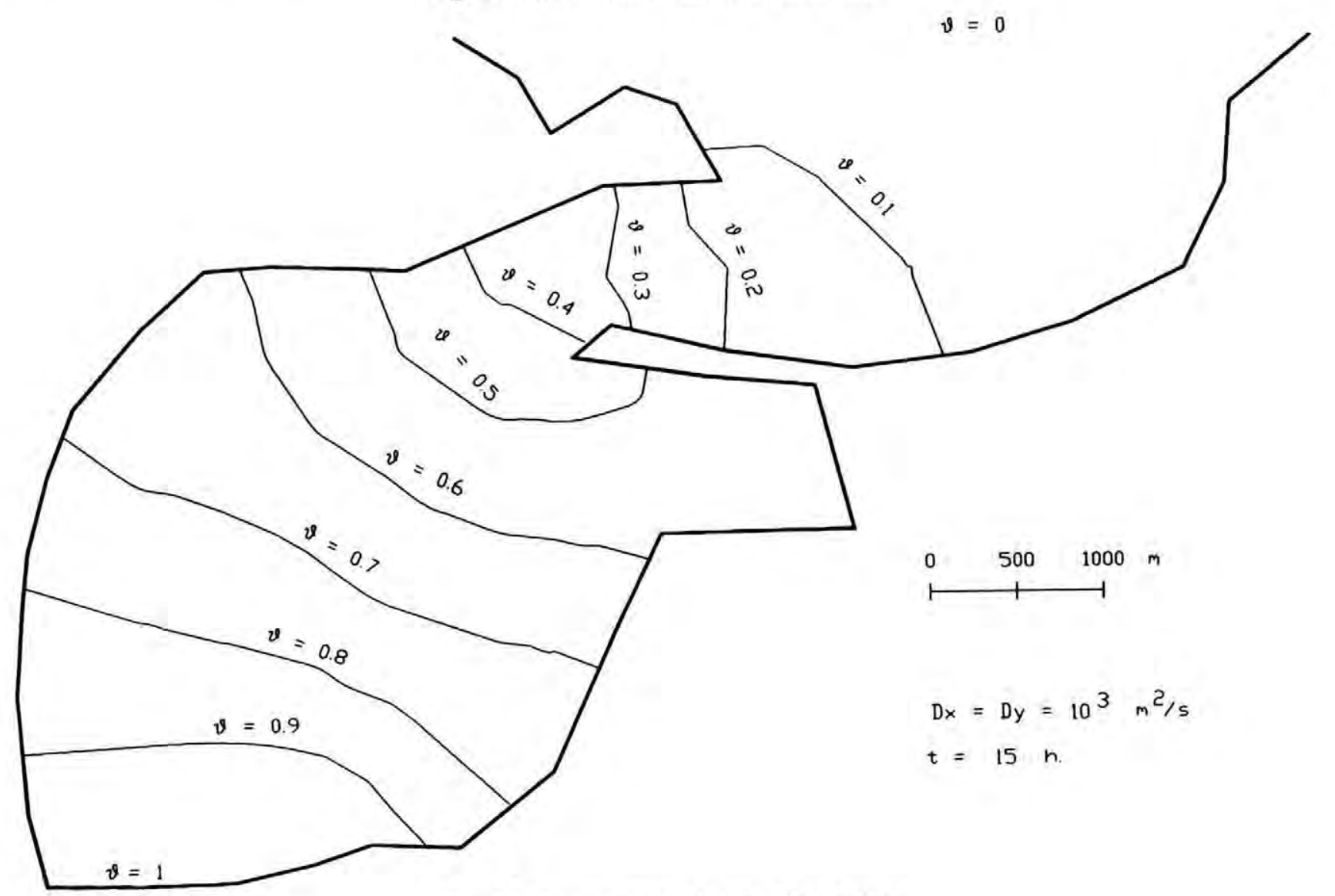

Fig. 18. Conservative substance (high tide). 
border it is supposed that water is not polluted and therefore its concentration is null. With this hypothesis, the values of the following variables are imposed:

$$
\begin{array}{ll}
\text { oceanic border: } & \Theta=0 \\
\text { border of the estuary of Astillero: } & \Theta=10^{3}
\end{array}
$$$$
\text { bacteria } / 100 \mathrm{ml}
$$

The following data are given:

$$
\begin{array}{ll}
\text { dispersion coefficients: } & D_{x}=D_{y}=200 \mathrm{~m}^{2} / \mathrm{s} \\
\text { decay coefficient: } & \alpha=10^{-5} \mathrm{~s}^{-1} \\
\text { interval: } & \Delta t=15 \mathrm{~s}
\end{array}
$$

Computer results are shown in Figs 22-25 where the isolines of the bacterium concentration are represented. The times corresponding to flood tide, high tide, ebb tide and low tide have been selected in this representation.

It may be interesting to study the sensitivity of the model with respect to the decay coefficient. With this objective, and the values of the dispersion coefficients kept constant, the program is executed for three different decay coefficients, namely, $\alpha=1 \times 10^{-5}$, $5 \times 10^{-5}$ and $10 \times 10^{-5} \mathrm{~s}^{-1}$. Figure 26 shows, with these coefficients, the results obtained on the coast near the city of Santander. First, it can be observed that an increase of the decay coefficient produces a decrease of the concentration of bacteria at every point of time. Second, the time variation of the concentration follows approximately the tide variation, i.e. a nearly harmonic variation of bacterium concentration occurs with the same period of the time but with a phase difference. For the three different decay coefficients the variation of concentration has nearly the same period and phase, and the maximum concentration occurs approximately $2 \mathrm{~h} 38 \mathrm{~min}$ after high tide. Therefore the difference of the phase does not depend on the decay coefficient, but only on the dispersion coefficient. All of these results are shown in Table 3, which shows the numerical values obtained for the maxima and minima of bacterium concentrations for every decay coefficient. In this table the extreme values of the concentration and the corresponding times are shown, in order to determine phase difference with respect to high and low tide.

\subsection{Stationary discharge at a point}

An effluent that discharges bacteria in a continuous manner is supposed at an indicated point, and the distribution of bacteria in the Bay at various instants is

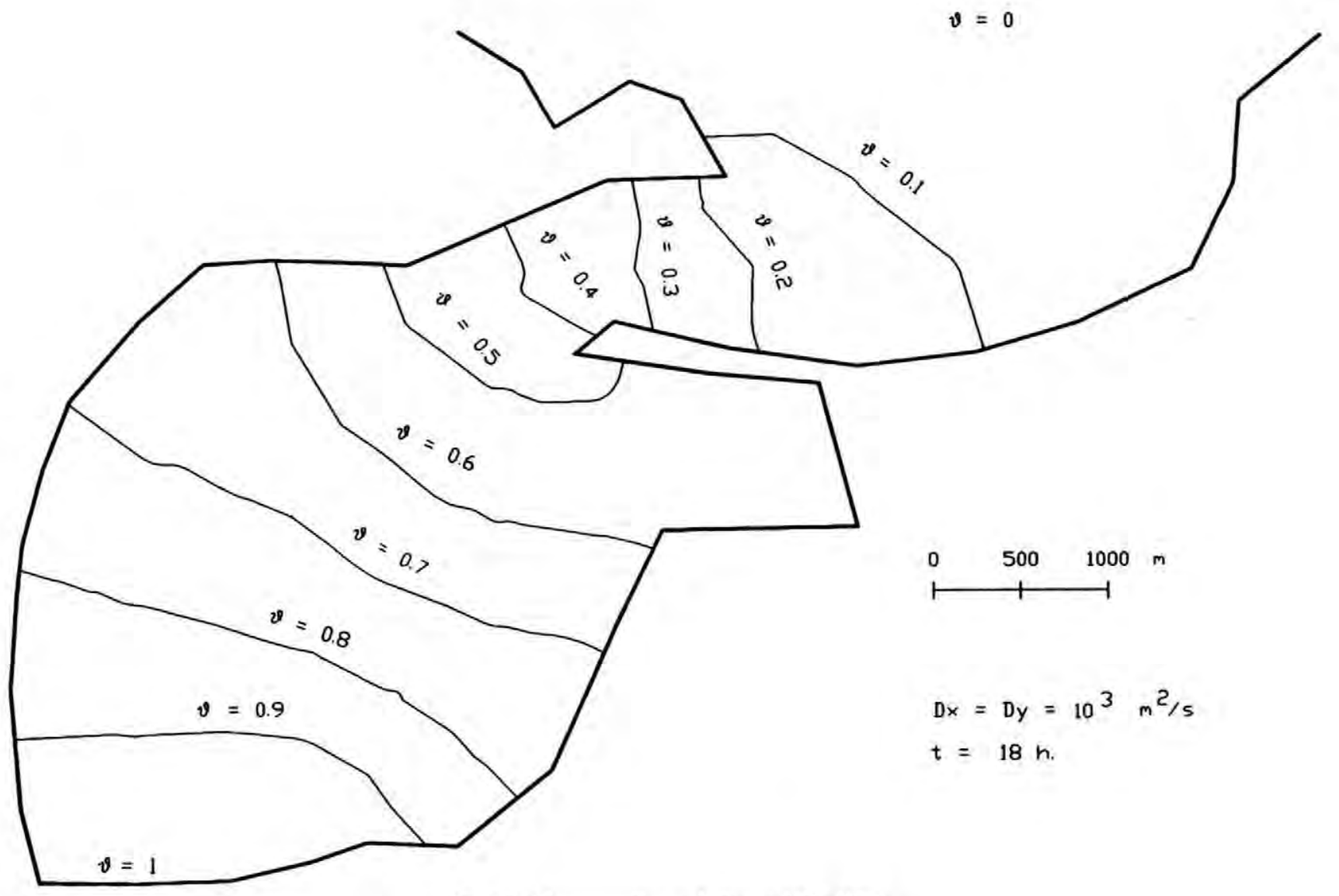

Fig. 19. Conservative substance (ebb tide). 
Table 3. Results of the distribution and evolution of the bacterium concentration

\begin{tabular}{|c|c|c|c|}
\hline \multicolumn{4}{|c|}{ Bacterium concentration $\left(D_{x}=X_{y}=200 \mathrm{~m}^{2} / \mathrm{s}\right)$} \\
\hline Decay coefficient $\left(\mathrm{s}^{-1}\right)$ & Characteristic & Time & $\overline{\text { Concentration }}$ \\
\hline$\alpha=1 \times 10^{-5}$ & $\begin{array}{l}\text { maximum } \\
\text { minimum } \\
\text { maximum } \\
\text { minimum }\end{array}$ & $\begin{array}{l}06 \mathrm{~h} 04 \mathrm{~m} 21 \mathrm{~s} \\
11 \mathrm{~h} 30 \mathrm{~m} 13 \mathrm{~s} \\
18 \mathrm{~h} 06 \mathrm{~m} 08 \mathrm{~s} \\
23 \mathrm{~h} 28 \mathrm{~m} 58 \mathrm{~s}\end{array}$ & $\begin{array}{l}599.64 \\
538.04 \\
599 \cdot 64 \\
538.04\end{array}$ \\
\hline$\alpha=5 \times 10^{-5}$ & $\begin{array}{l}\text { maximum } \\
\text { minimum } \\
\text { maximum } \\
\text { minimum }\end{array}$ & $\begin{array}{l}06 \mathrm{~h} 04 \mathrm{~m} 21 \mathrm{~s} \\
11 \mathrm{~h} 30 \mathrm{~m} 13 \mathrm{~s} \\
18 \mathrm{~h} 06 \mathrm{~m} 08 \mathrm{~s} \\
23 \mathrm{~h} 28 \mathrm{~m} 58 \mathrm{~s}\end{array}$ & $\begin{array}{l}549 \cdot 64 \\
493 \cdot 84 \\
549 \cdot 64 \\
493 \cdot 84\end{array}$ \\
\hline$\alpha=10 \times 10^{-5}$ & $\begin{array}{l}\text { maximum } \\
\text { minimum } \\
\text { maximum } \\
\text { minimum }\end{array}$ & $\begin{array}{l}06 \mathrm{~h} 04 \mathrm{~m} 21 \mathrm{~s} \\
11 \mathrm{~h} 30 \mathrm{~m} 13 \mathrm{~s} \\
18 \mathrm{~h} 06 \mathrm{~m} 08 \mathrm{~s} \\
23 \mathrm{~h} 28 \mathrm{~m} 58 \mathrm{~s}\end{array}$ & $\begin{array}{l}496 \cdot 00 \\
446 \cdot 74 \\
496 \cdot 00 \\
446 \cdot 74\end{array}$ \\
\hline
\end{tabular}

Tide level

\begin{tabular}{lcr}
\hline Characteristic & Time & Tide level (m) \\
\hline high tide & $03 \mathrm{~h} 25 \mathrm{~m} 59 \mathrm{~s}$ & 1.9674 \\
low tide & $09 \mathrm{~h} 25 \mathrm{~m} 21 \mathrm{~s}$ & -1.9457 \\
high tide & $15 \mathrm{~h} 21 \mathrm{~m} 40 \mathrm{~s}$ & 1.9674 \\
low tide & $21 \mathrm{~h} 30 \mathrm{~m} 11 \mathrm{~s}$ & -1.9457 \\
\hline
\end{tabular}

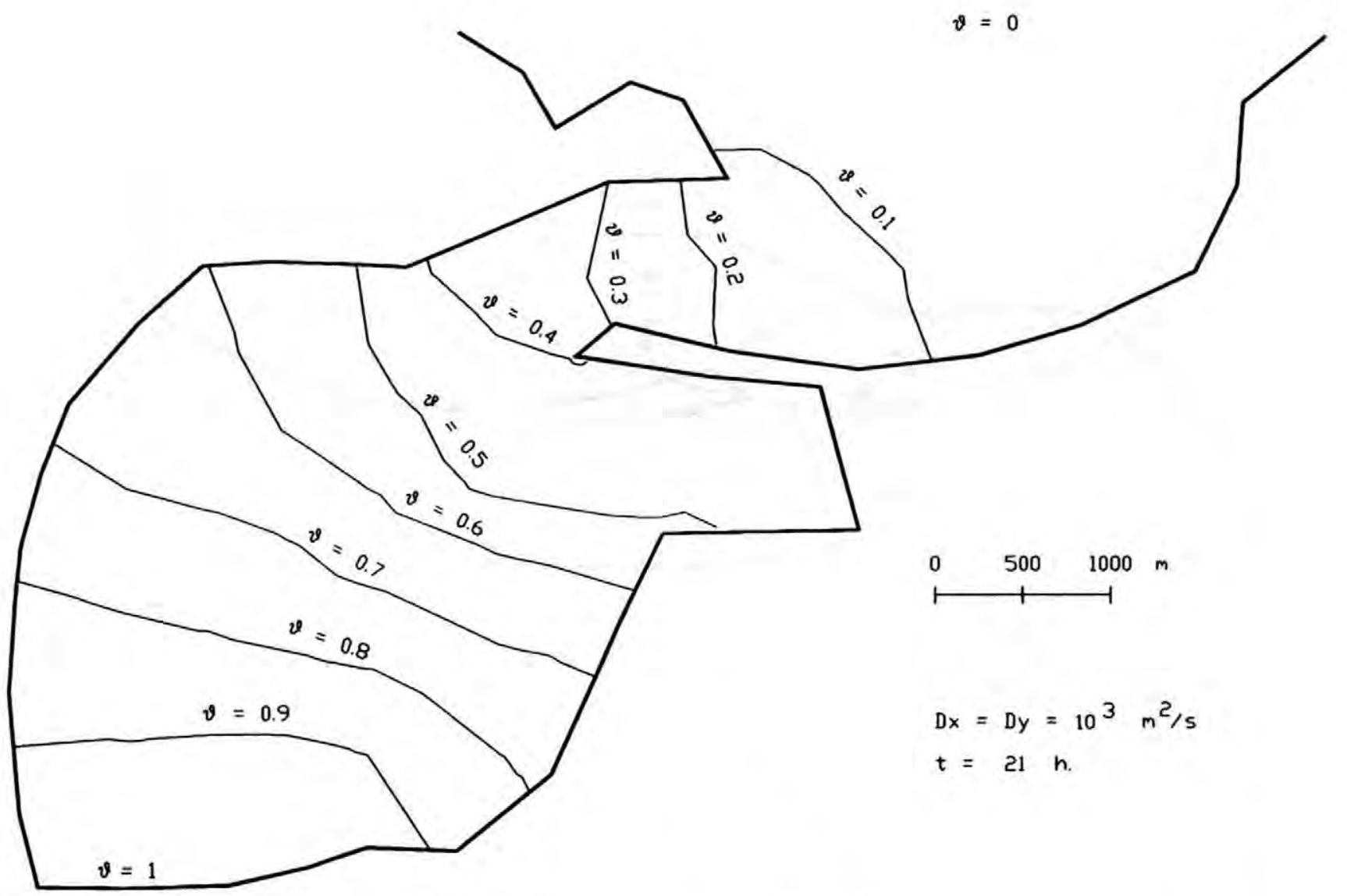

Fig. 20. Conservative substance (low tide). 


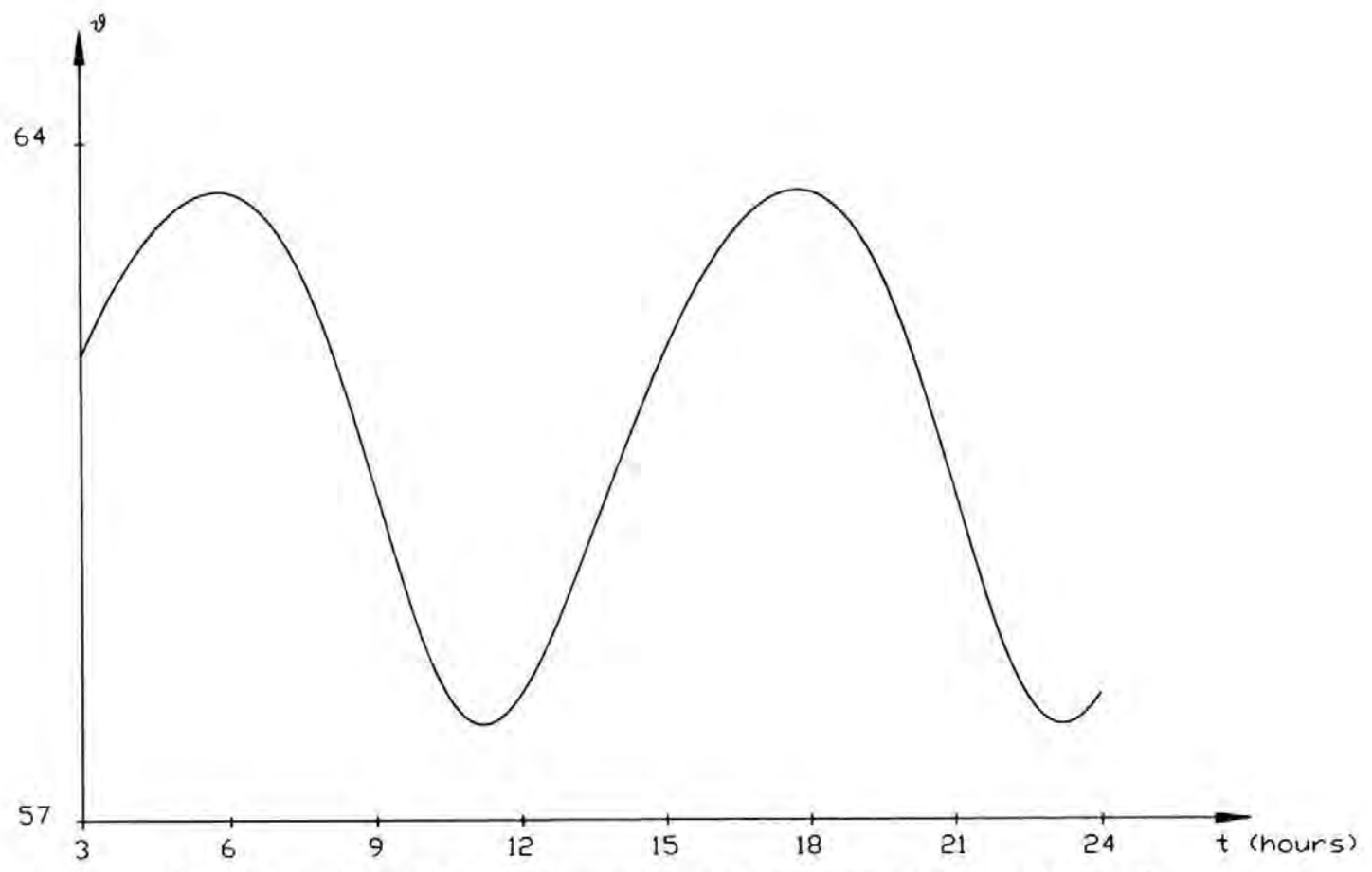

Fig. 21. Evolution of the concentration on the coast near the city of Santander.

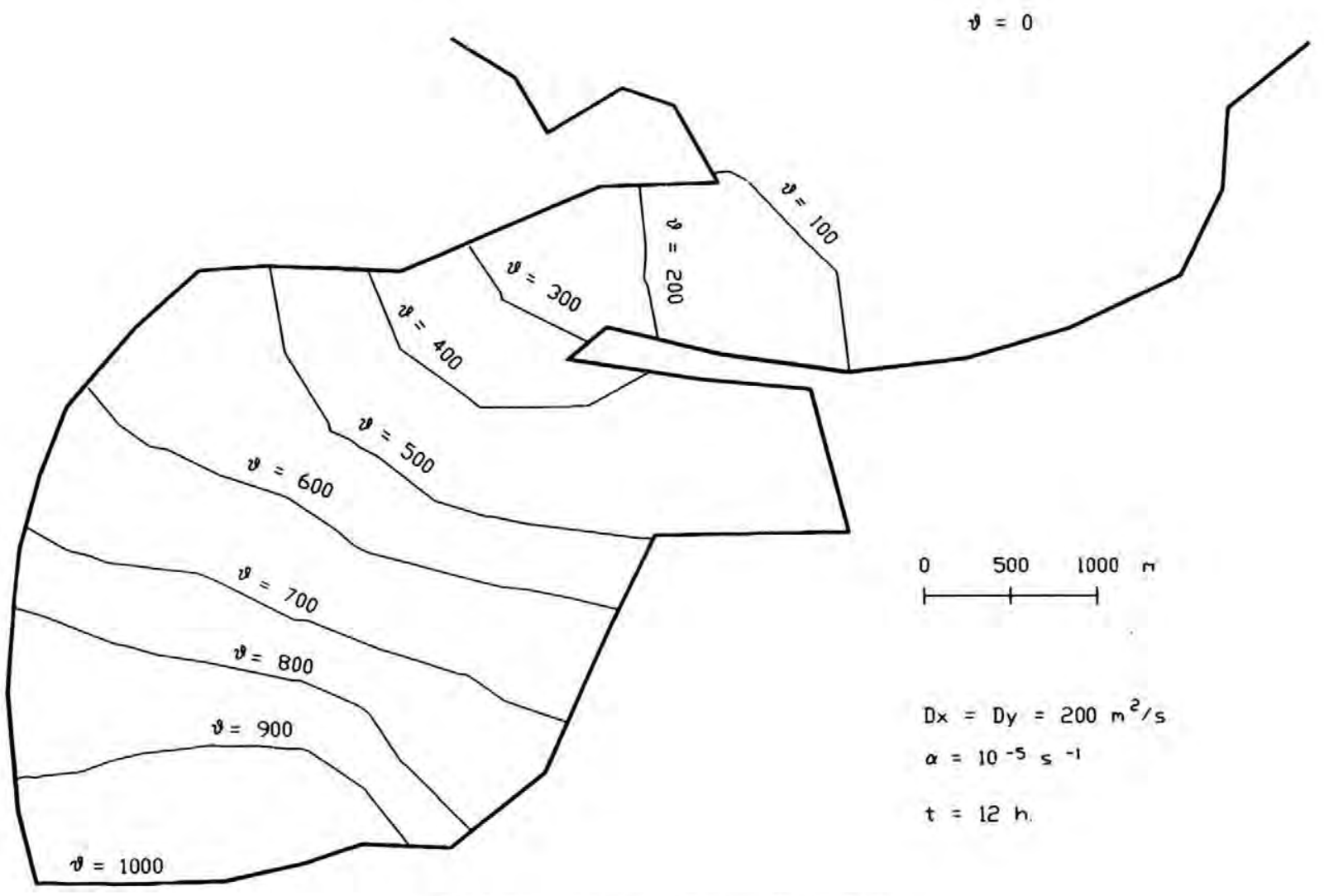

Fig. 22. Bacterium population (flood tide). 


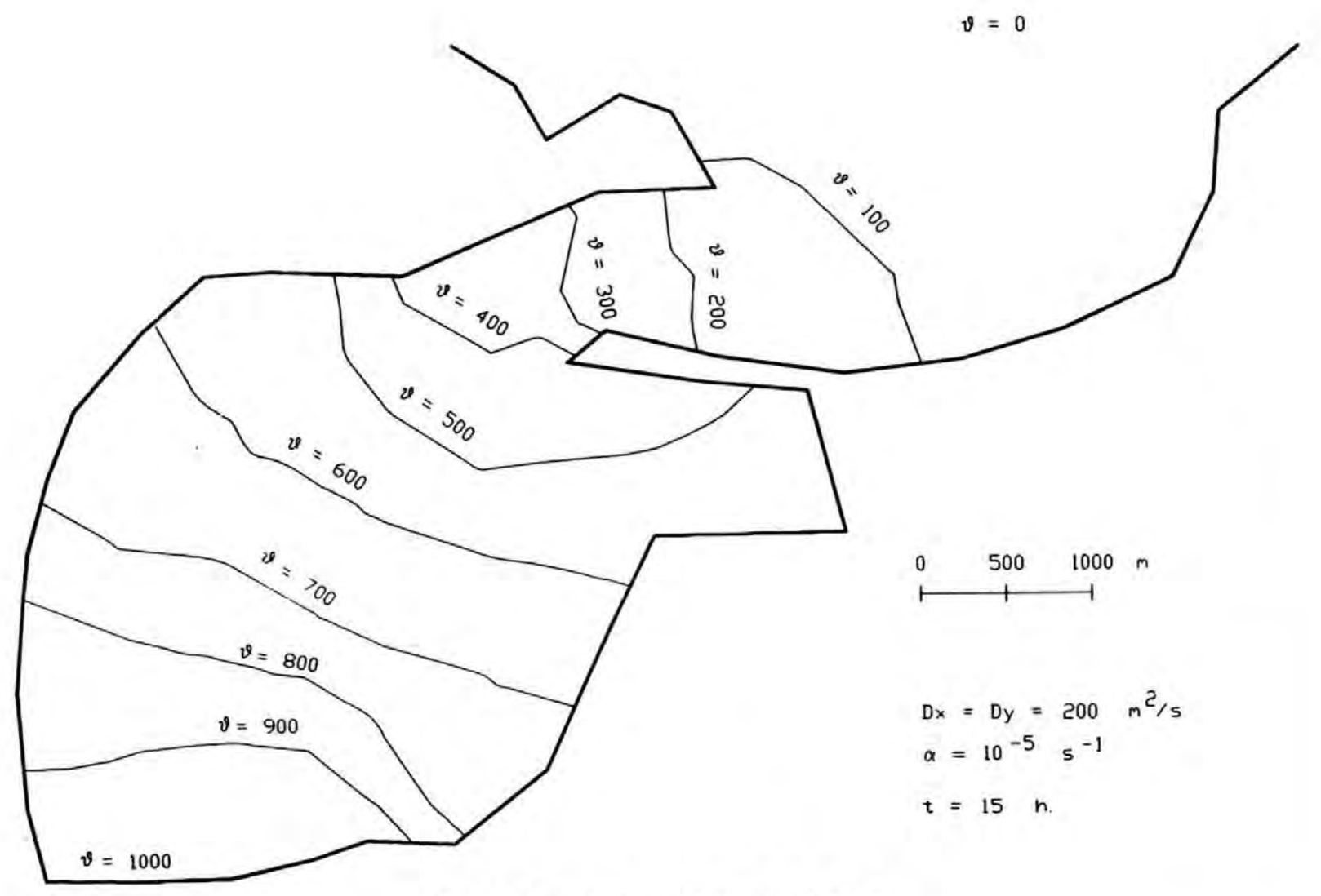

Fig. 23. Bacterium population (high tide).

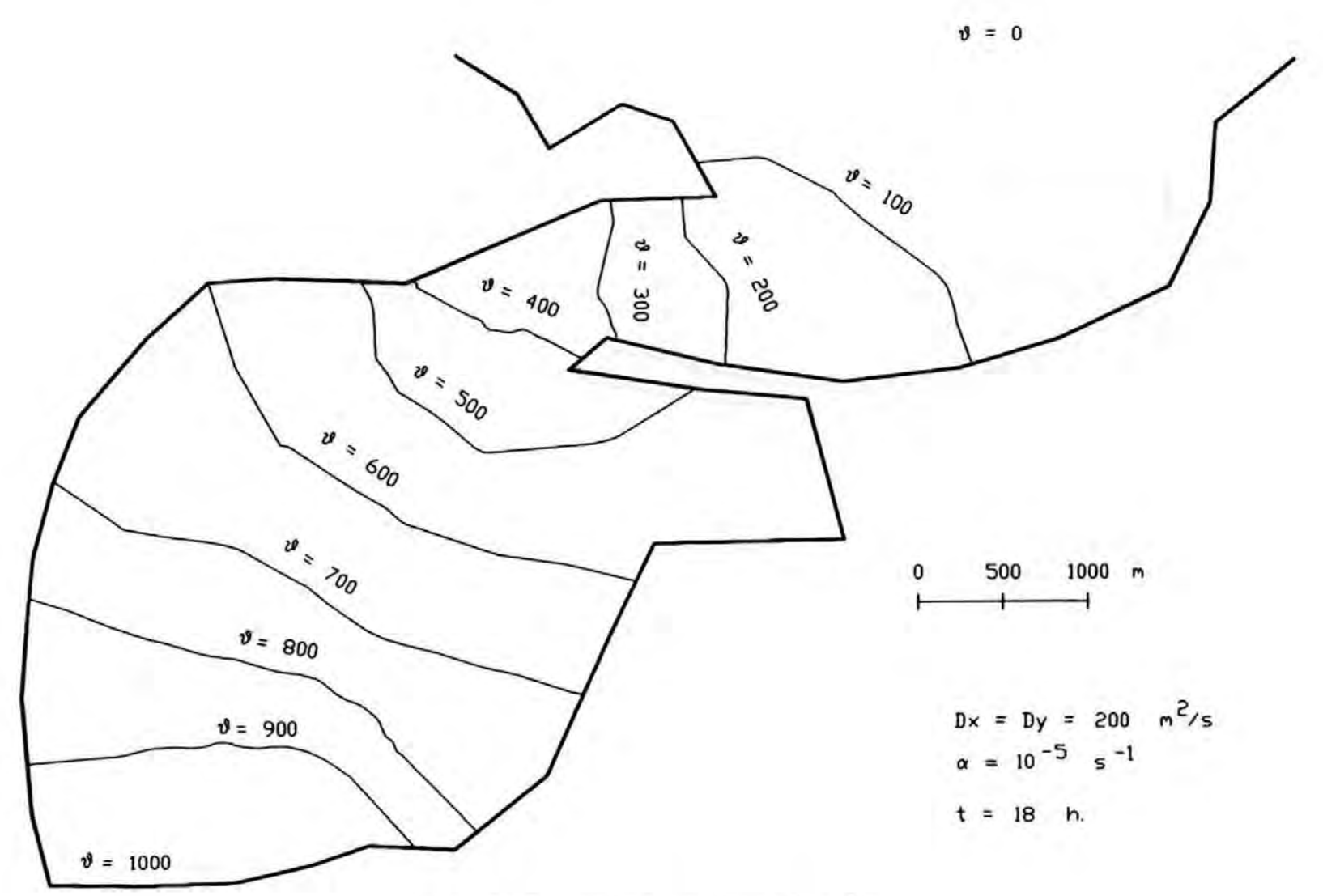

Fig. 24. Bacterium population (ebb tide). 


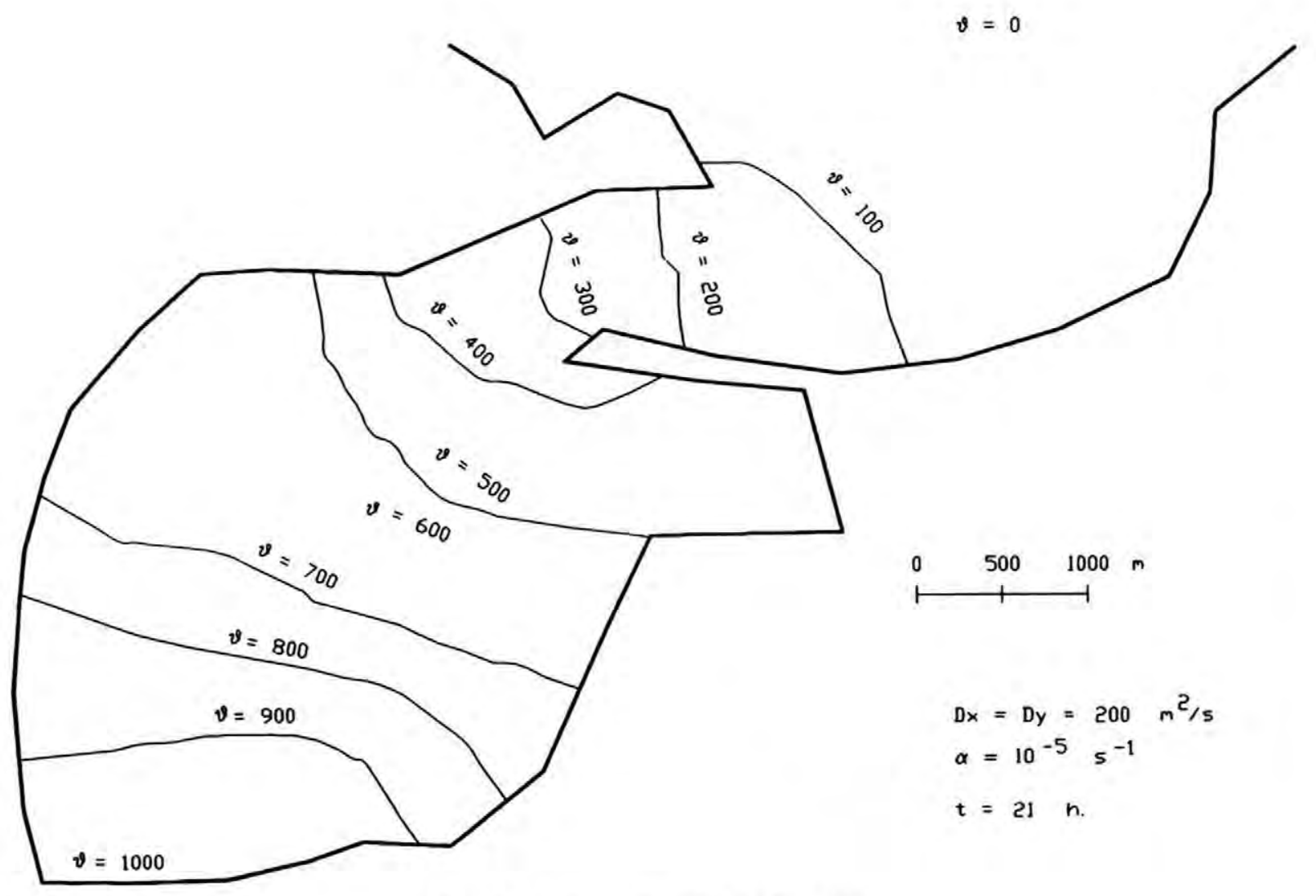

Fig. 25. Bacterium population (low tide).

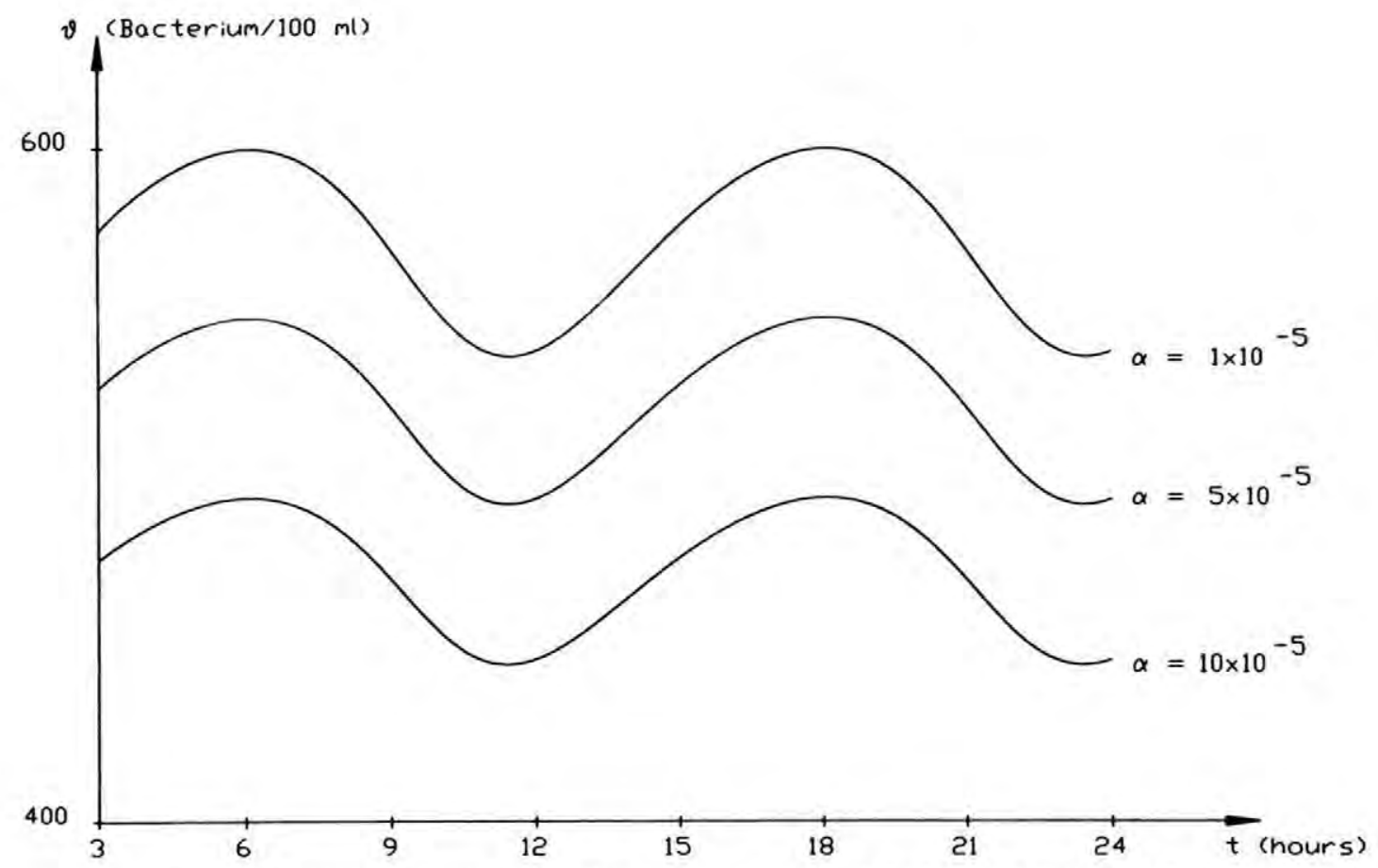

Fig. 26. Concentration near the city of Santander as a function of decay coefficient. 


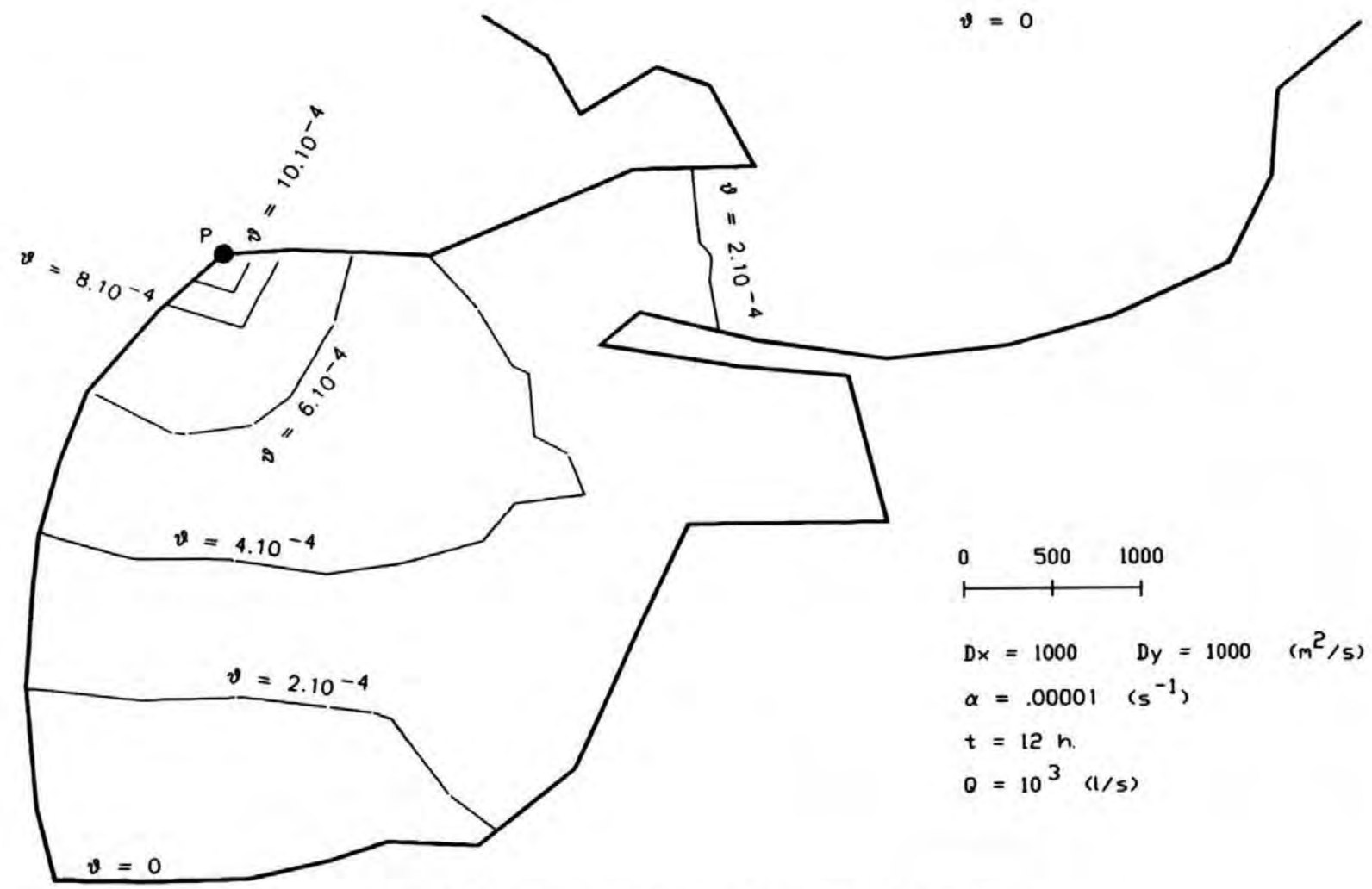

Fig. 27. Stationary discharge at point $P$ (flood tide).

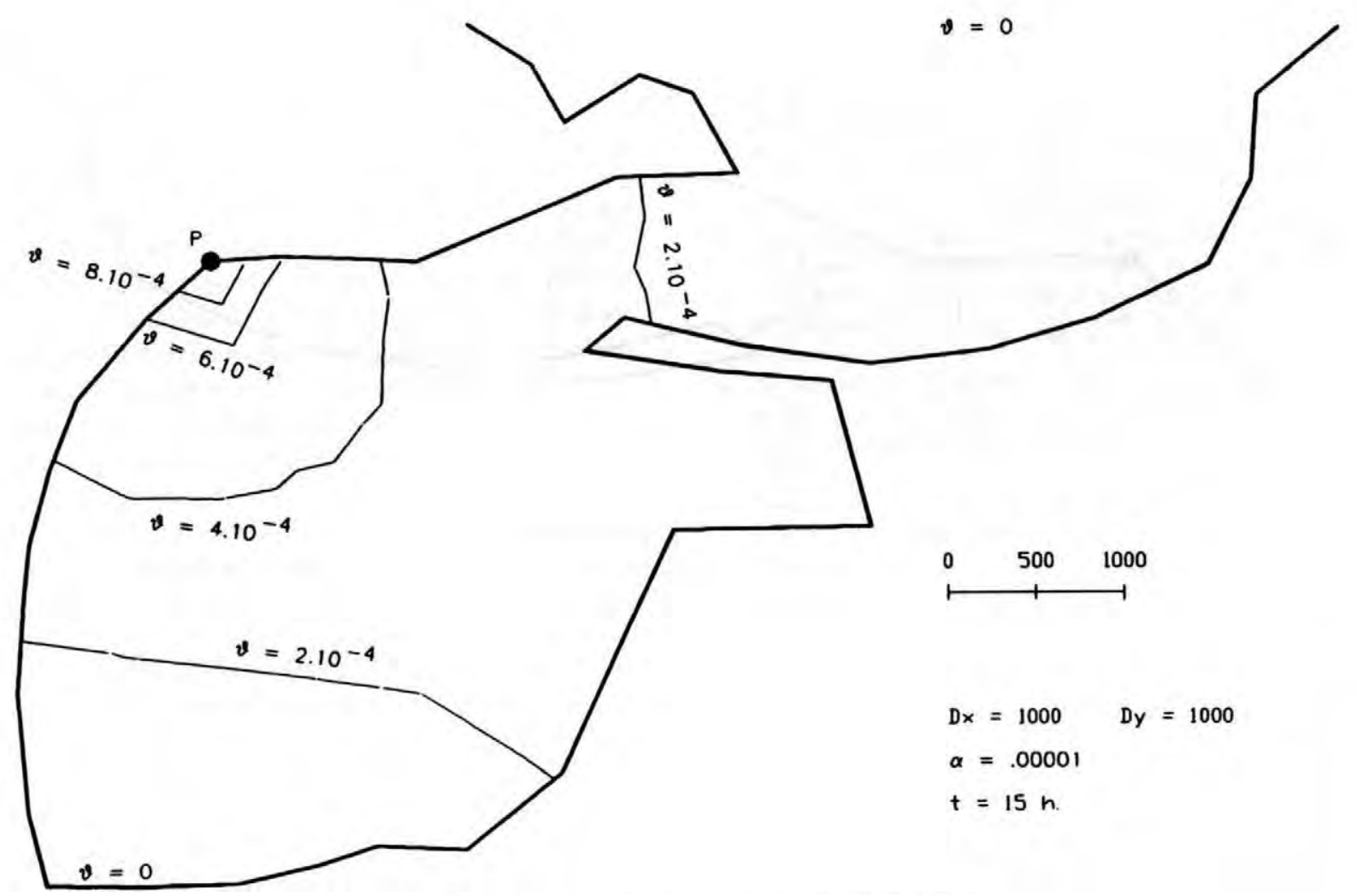

Fig. 28. Stationary discharge at point $\mathbf{P}$ (high tide). 


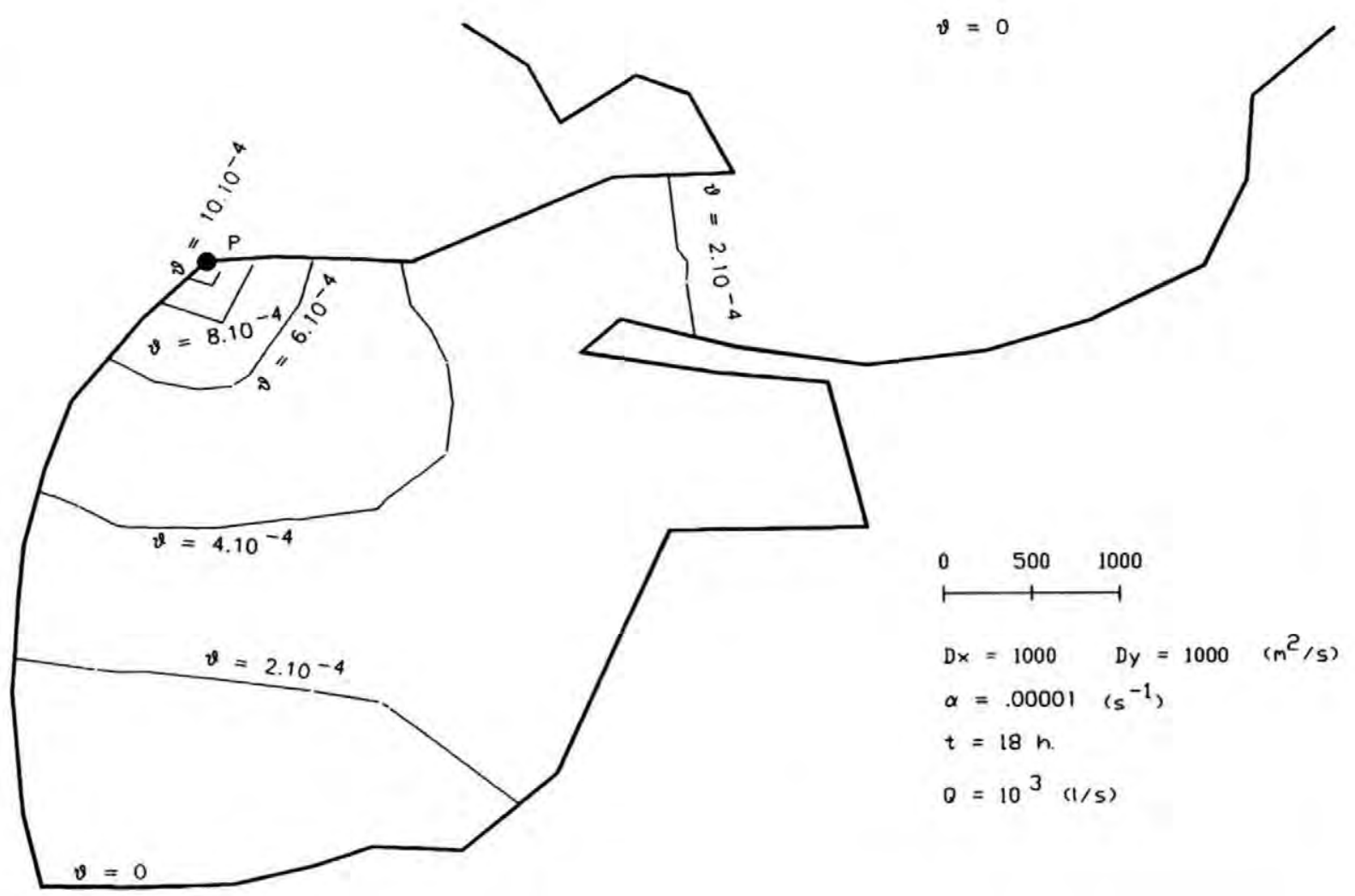

Fig. 29. Stationary discharge at point $\mathrm{P}$ (ebb tide).

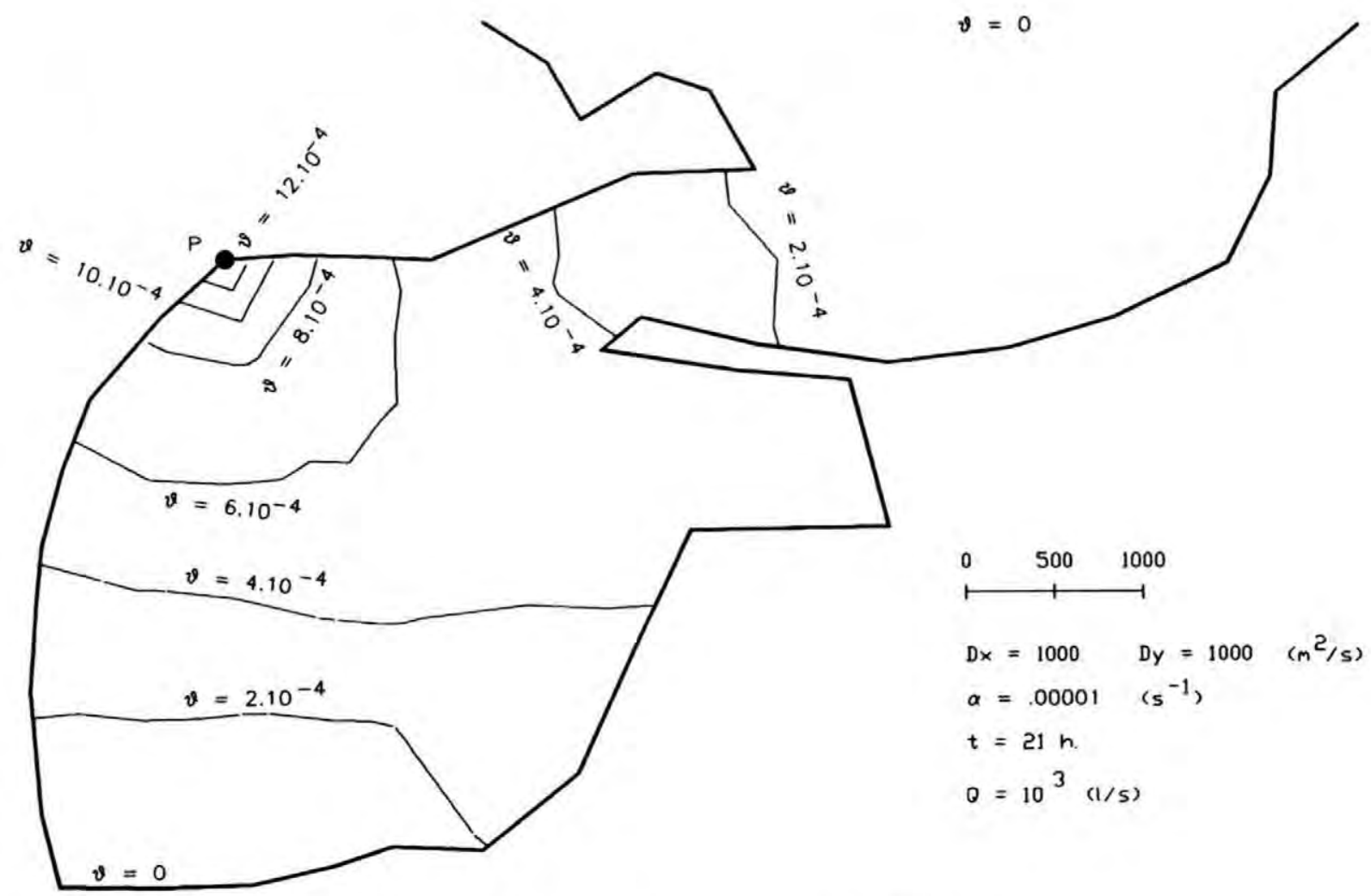

Fig. 30. Stationary discharge at point $P$ (low tide). 
studied. It is considered that the concentration on the southern border, where a river enters, and in the open sea, is null. For this study the following data are taken:

$\begin{array}{ll}\text { discharge strength: } & Q=10^{3} \mathrm{l} / \mathrm{s} \\ \text { density of the effluent: } & \theta_{\mathrm{e}}=10^{3} \mathrm{bacteria} / 100 \mathrm{ml} \\ \text { decay coefficient: } & \alpha=10^{-5} \mathrm{~s}^{-1} \\ \text { dispersion coefficient } & D_{x}=D_{y}=10^{3} \mathrm{~m}^{2} / \mathrm{s} \\ \text { time interval: } & \Delta t=15 \mathrm{~s} \\ \text { oceanic and south border: } & \theta=0\end{array}$

Figures 27-30 show the results obtained by the model. The concentration isolines are represented therein at instants that correspond to flood, high, ebb and low tide, respectively.

\section{CONCLUSIONS}

By a model of the type presented here, it is possible to determine the evolution of the velocity, elevation of the sea level, and contaminant concentration at every point of an estuary with arbitrary geometry. With the tool developed in this paper the response of the estuary to the different external inputs can be obtained and coastal planning is facilitated. It is also possible to find tentative better locations of the different discharge points to the actual ones; moreover it is possible to access their corresponding environmental impact over the estuary or affected coastal zone.

For the discretization of the domain, triangular linear elements have been used. Time integration of the hydrodynamic equations has been carried out by means of an explicit two-step method, and the dispersion equation by an iterative implicit scheme. With the use of this technique the required memory of the computer is minimized but at the expense of a greater CPU time. The model has shown its efficiency for domain dimensions of the order of the Bay of Santander.

The size of the finite element mesh is one predominant factor for this model to reach an appropriate accuracy level. It is confirmed that for mesh generation, prior knowledge of the position of the different sources is required. Node density should be increased at zones near the prompt discharges and in regions where strong gradients of the dependent variable are presented. Likewise, if the ratio between the areas of the contiguous elements is greater than 2 , oscillations in the solution and numerical instability may be produced. To ensure the stability of the model, the interval should verify the conditions $\Delta t \leq 0 \cdot 2(\Delta x / v)$ and $\Delta t \leq 0 \cdot 3\left(\Delta x^{2} / 2 D\right)$.

The computed hydrodynamics about the Bay of Santander agrees with the experimental results obtained by the Instituto Español de Oceanografia. ${ }^{18}$ Nevertheless, it is necessary to mention the scarcity of previous experimental data.

\section{REFERENCES}

1. Bailey, C. A., McCullough, C. G. \& Gunnerson, C. G., Mixing and dispersion studies in San Francisco Bay. Journal of the Sanitary Engineering Division ASCE, 1966, 92(SA5), 23-45.

2. Cunge, J. A., Holly Jr, F. M. \& Schwartz, S., Mathematical modelling study of pollution transport in the Bay of Saint-Brieuc, France. SOGREAH, Ingenieurs Conseils, 1982.

3. Fischer, H. B., Dispersion predictions in natural streams. Journal of the Sanitary Engineering Division ASCE, 1968, 94(SA5), 927-943.

4. Lager, J. A., Effluent disposal in South San Francisco Bay. Journal of the Sanitary Engineering Division ASCE, 1968 , 94(SA2).

5. Ehlig, C., Comparison of numerical methods for solution of the diffusion-convection equation in one and two dimensions. In Finite Elements in Water Resources. Pentech Press, London, 1976.

6. Villoria, C., Garcia, R. \& Varela, E., Prediction of current and sediment deposition patterns in Puerto Miranda oil terminal using 2-D mathematical models. Proc. 23rd Int. Conf. (Coastal Engineering) Vol. 3, pp. 2724-2734. Venice, Italy, October 1992.

7. Garzon, A. \& D'Alpaos, L., A modified method of characteristic technique combined with Galerkin finite element method to solve shallow water mass transport problems. In Proc. 23rd Int. Conf. (Coastal Engineering), Vol. 3, pp. 3068-3080. Venice, Italy, October 1992.

8. Sladkevich, M. \& Rubin, H., Modelling of sea currents in the Gulf of Eilat (Aqaba) by 2-D and 3-D models. In Proc. First Int. Conf. Mediterranean Coastal Environment, MEDCOAST 93, Vol. 2, pp. 1135-1151. Antalya, Turkey, November 1993.

9. Juang, J. T. \& Tseng, D. H., The mutuality of current and pollution in Yin-Yang Bay (Taiwan). In Proc. First Int. Conf. Mediterranean Coastal Environment, MEDCOAST 93, pp. 1153-1168. Antalya, Turkey, November 1993.

10. Venturi, M., Ioveniti, L. \& Preti, M., Numerical modelling of estuarine fine sediment dispersion in the coastal zone. In Proc. First Int. Conf. Mediterranean Coastal Environment, MEDCOAST 93, Vol. 2, pp. 1169-1180. Antalya, Turkey, November 1993.

11. Tabuenca, P., Cardona, J. \& Samartin, A., Numerical model for the study of hydrodynamics on bays and estuaries. Applied Mathematical Modelling., 1992, 16 (February).

12. Ninomiya, H. \& Onishi, K., Flow Analysis Using a PC. Computational Mechanics Publications, CRC Press, Boca Raton, FL, 1991.

13. Pinder, G. F. \& Gray, W. G., Finite Element Simulation in Surface and Subsurface Hydrology. Academic Press, New York, 1977.

14. Cardona, J. \& Samartin, A., Numerical models for coastal zone management. Ocean \& Shoreline Management, 1989, 12, 571-586.

15. Connor, J. J. \& Brebbia, C. A., Finite Element Techniques for Fluid Flow. Newnes-Butterworths, London, 1976.

16. Cardona, J., Un modelo para el estudio de la contaminación en fluidos basado en el método de los elementos finitos. Aplicación a la Bahía de Santander. PhD Thesis, Universidad de Cantabria, Santander, 1986. 
17. Dailey, J. E. \& Harleman, D. R. F., A numerical model of transient water quality in a one-dimensional estuary based on the finite element method. In Numerical Methods in Fluid Dynamics, eds C. A. Brebbia and J. J. Connor. Pentech Press, London, 1974, pp. 412-439.
18. Castillejo, F. F., Lavin, A. \& Esteban, A., Medidas de corrientes en la Bahía de Santander y zona adyacente por medio de flotadores. Estudio básico para el conocimiento de los niveles de contaminación e hidrodinámica de la Bahía de Santander. CID, Vol. 1, p. 1079. 